\title{
The lysosome and intracellular signalling
}

\section{Geoffrey G. Hesketh ${ }^{1}$, Lena Wartosch ${ }^{2}$, Luther J. Davis ${ }^{2}$, Nicholas A. Bright ${ }^{2}$ and J. Paul Luzio ${ }^{2 *}$}

\author{
${ }^{1}$ Lunenfeld-Tanenbaum Research Institute, Sinai Health System, Toronto, ON \\ M5G 1X5, Canada and ${ }^{2}$ Cambridge Institute for Medical Research and \\ Department of Clinical Biochemistry, University of Cambridge School of Clinical \\ Medicine, Wellcome Trust/MRC Building, Cambridge Biomedical Campus, Hills \\ Road, Cambridge, CB2 OXY, U.K.
}

*Corresponding author: J. Paul Luzio, jpl10@cam.ac.uk

\section{Abstract}

In addition to being the terminal degradative compartment of the cell's endocytic and autophagic pathways, the lysosome is a multifunctional signaling hub integrating the cell's response to nutrient status and growth factor/hormone signaling. The cytosolic surface of the limiting membrane of the lysosome is the site of activation of the multi-protein complex mTORC1 (mammalian target of rapamycin complex 1), which phosphorylates numerous cell growth-related substrates, including TFEB (transcription factor EB). Under conditions in which mTORC1 is inhibited including starvation, TFEB becomes dephosphorylated and translocates to the nucleus where it functions as a master regulator of lysosome biogenesis. The signaling role of lysosomes is not limited to this pathway. They act as an intracellular $\mathrm{Ca}^{2+}$ store, which can release $\mathrm{Ca}^{2+}$ into the cytosol for both local effects on membrane fusion and pleiotropic effects within the cell. The relationship and cross-talk between the lysosome and $\mathrm{ER} \mathrm{Ca}^{2+}$ stores play a role in shaping intracellular $\mathrm{Ca}^{2+}$ signaling. Lysosomes also perform other signaling functions, which are discussed. Current views of the lysosomal compartment recognise its dynamic nature. It includes endolysosomes, autolysosome and storage lysosomes that are constantly engaged in fusion/fission events and lysosome regeneration. How signaling is affected by individual lysosomal organelles being at different stages of these processes and/or at different sites within the cell is poorly understood, but is discussed. 


\section{The discovery of the lysosomal membrane as a signaling hub}

Less than ten years ago, a description of the role of the lysosome in intracellular signaling would likely have focused mainly on its function in the down-regulation, by degradation, of endocytosed cell surface receptors. An extensive literature had built up on the endocytic pathways taken by different receptors, including the role of endosomes as signaling platforms, the mechanisms of sorting into recycling pathways, the loss of signaling when they were sorted into the ILVs (intrauminal vesicles) of MVBs (multivesicular bodies), and delivery to lysosomes for degradation by proteases (for reviews see (Platta and Stenmark 2011; Alonso and Friedman 2013; Goh and Sorkin 2013; Bowman et al. 2016)). However, two papers in Science published at the end of the last decade radically changed the perception of the lysosome's role in intracellular signaling. David Sabatini's group found that whereas in starved, cultured mammalian cells, mTOR (mammalian target of rapamycin) was distributed throughout the cytoplasm, amino acid feeding resulted in a substantial fraction translocating to late endosomal and lysosomal compartments (Sancak et al. 2008). Initially using a systems biology approach, Andrea Ballabio's group discovered that many lysosomal genes exhibited coordinated transcriptional behavior and are regulated by TFEB (transcription factor EB), which translocates from the cytoplasm to the nucleus under various conditions of lysosomal stress and acts as a master regulator of lysosome biogenesis (Sardiello et al. 2009). The Sabatini and Ballabio research groups went on to show that TFEB and the multi-protein complex mTORC1 (mTOR complex 1, reviewed in (Eltschinger and Loewith 2016)) colocalize on the lysosome membrane where mTORC1 phosphorylates TFEB (Settembre et al. 2012). Under conditions in which mTORC1 is inhibited, they observed that TFEB becomes dephosphorylated and translocates to the nucleus. The discovery of a lysosome-to-nucleus signaling mechanism involving mTORC1 and TFEB, together with subsequent work showing that multiple signals are sensed and integrated on the lysosomal surface to regulate the activation state of $\mathrm{mTORC} 1$, has led to the current consensus that the lysosomal membrane is a major hub of intracellular signalling, which regulates cell metabolism and growth (Perera and Zoncu 2016).

In addition to these major discoveries about the role of the lysosomal 
membrane in mTORC1 and TFEB signaling, there has also been a growing realization over the past two decades that the mammalian lysosomal compartment is heterogeneous and is made up of less acidic/neutral lysosomes, acidic endolysosomes and autolysosomes, formed respectively by fusion of late endosomes or autophagosomes with lysosomes, as well as organelles that are at different stages of maturation on lysosome regeneration pathways (Figure 1). As more and more components of the molecular machinery of lysosome fusion and re-formation are discovered there is also an increasing emphasis on how these processes are regulated and how they contribute to or are affected by intracellular signaling.

\section{The lysosomal compartment and the lysosome}

\section{fusion/regeneration cycle}

Lysosomes were originally discovered in the mid-twentieth century as membrane-bound organelles containing acid hydrolases and were rapidly recognized as the terminal degradative compartment of the endocytic and autophagic pathways (reviewed in (de Duve 2005)). Nowadays, we are more aware of the dynamic nature of the endocytic pathway and the role of the lysosome fusion/regeneration cycle in determining the complexity of the late endosomal and lysosomal compartments (Figure 1). The endocytic pathway taken by macromolecules en route to lysosomes has been well described (Luzio et al. 2007; Woodman and Futter 2008; Huotari and Helenius 2011; Luzio et al. 2014), as has the autophagic (i.e. macroautophagic) pathway (Feng et al. 2014; Bento et al. 2016). The delivery of endocytosed cargo to lysosomal acid hydrolases is achieved by kiss and run as well as full fusion events between late endosomes, also known as MVBs (multi-vesicular bodies), and lysosomes (Bright et al. 2005; Bright et al. 2016). These events result in the formation of endolysosomes, which are hybrid organelles with characteristics of both late endosomes and lysosomes. It is in endolysosomes that hydrolytic degradation commences and these organelles can undertake further, multiple, fusion events with other late endosomes and lysosomes.

\subsection{Lysosome fusion with endosomes and autophagosomes - core machinery and regulation}

The molecular mechanism of late endosome-lysosome fusion is broadly understood and, like other fusion events in secretory and endocytic 
membrane traffic pathways, involves tethering, docking and phospholipid bilayer fusion steps (Luzio et al. 2007). Tethering requires the heterohexameric HOPS (homotypic fusion and vacuole protein sorting), complex (Wartosch et al. 2015) . In the yeast Saccharomyces cerevisiae, HOPS, which structurally is a three-legged filamentous complex (Chou et al. 2016), is recruited directly to the limiting membrane of the vacuole (the yeast equivalent of the mammalian lysosome) by Ypt7p, the ortholog of the mammalian small GTPase Rab7 (Hickey and Wickner 2010). However, in mammalian cells, the Rab7 effector RILP (Lin et al. 2014; van der Kant et al. 2015) as well as the small GTPase Arl8b are needed for HOPS recruitment to late endosomal/lysosomal membranes (Khatter et al. 2015). Following tethering, the late endosome-lysosome fusion process requires the formation of a trans-SNARE (soluble $\mathrm{N}$-ethylmaleimide-sensitive factor attachment protein receptor) complex consisting of three Q-SNAREs, namely syntaxin 7 (a Qa-SNARE), Vti1b (a Qb-SNARE), syntaxin 8 (a Qc-SNARE) and VAMP7 (an R-SNARE), which interact to form a parallel four-helix bundle that brings the two phospholipid bilayers together to enable membrane fusion (Pryor et al. 2004). It has been suggested that in vivo the requirement for VAMP7 may be complemented by another R-SNARE, VAMP8 (Pols et al. 2013).

Components of the molecular machinery required for autophagosomelysosome fusion have also been discovered. The HOPS complex is required (Jiang et al. 2014), but an additional factor involved in tethering is the Rab7 effector and HOPS-interacting protein, PLEKHM1 (pleckstrin homology domain containing protein family member 1 ), which functions as a central hub in integrating endocytic and autophagic pathways at the lysosome (McEwan et al. 2015; McEwan and Dikic 2015). PLEKHM1 contains an LC3 (microtubule-associated protein 1 light chain 3)-interacting region that mediates its binding to autophagosomes via LC3 or GABARAP (Gammaaminobutyric acid type A receptor-associated protein) members of the ATG8 (autophagy related 8) family of proteins, which are essential for autophagosome-lysosome fusion (Nguyen et al. 2016). The recruitment of PLEKHM1 and HOPS may also be regulated by the cholesterol sensing Rab7 effector ORP1L which localizes to autophagosomes and under low cholesterol conditions is involved in the formation of autophagosome-ER (endoplasmic 
reticulum) membrane contact sites (Wijdeven et al. 2016). The trans-SNARE complex required for autophagosome-lysosome fusion has been identified as consisting of syntaxin 17 as the Qa-SNARE, SNAP-29 as the Qbc-SNARE and VAMP8 as the R-SNARE (Itakura et al. 2012). A role for an alternative RSNARE, VAMP7, has been proposed (Fader et al. 2009).

What is much less clear than our knowledge of the minimal protein machinery required for lysosome fusion with either late endosomes or autophagosomes is our understanding of how these processes are regulated. Relatively little is known about how flux through the late endocytic pathway or the route taken are regulated, although it is clear that regulation does occur. For example, whereas we have a good understanding of how EGF (epidermal growth factor) binding to its receptor at the plasma membrane leads to receptor phosphorylation, ubiquitination, endocytosis and sorting into endosomal ILVs, as well as intracellular signaling (Sorkin and Goh 2008), the regulation of its passage through late endocytic compartments is less well understood. EGF stimulates both the number of MVBs per unit of cytoplasm and the number of ILVs per MVB, an effect specific to the MVBs containing the EGF receptor (White et al. 2006), but the mechanism is unclear. Even within a single MVB, ILVs are of different sizes and are formed by more than one mechanism, with evidence that a competitive relationship exists between the well-described ESCRT (endocytic sorting complex required for transport) pathway for ILV formation and sorting of ubiquitinated cargo such as the EGF receptor and an ESCRT-independent pathway, which requires the tetraspanin membrane protein CD63 (Edgar et al. 2014). Details of the latter pathway are very sketchy, although recent work on the role of tetraspanins in MVB formation in yeast may provide some clues (MacDonald et al. 2015).

Whilst it is also known that lysosomes fuse with late endosomes much more efficiently than they do with early endosomes, how fusion is signaled is only poorly understood. A partial explanation is the Rab5/Rab7 switch that occurs as the endosome matures allowing different Rab effectors to be recruited (reviewed in (Huotari and Helenius 2011)). However, there is also a need to ensure that the MVBs that fuse have been depleted of recycling membrane proteins such as the mannose 6-phosphate receptors and that formation of ILVs, as well as sorting of ubiquitinated cargo into ILVs by the 
ESCRT pathway, is complete. Although it is not known how a mature MVB is identified for fusion, it could be as simple as the loss of ubiquitinated cargo from the limiting membrane. There may also be a role for some components of the ESCRT pathway, since an involvement of ESCRT-III proteins in fusion of late endosomes with lysosomes, separate to the requirement for ILV formation has been described (reviewed in (Metcalf and Isaacs 2010)).

Efficient fusion of lysosomes with late endosomes requires release of luminal $\mathrm{Ca}^{2+}$ at a late stage in the fusion process (Pryor et al. 2000). Although the mechanism by which this aids membrane fusion is not resolved, it may well underlie the effects of other perturbations of lysosome fusion. For example, Niemann-Pick type-C1-deficient cells have a defect in fusion of lysosomes with endosomes, which is likely to be a consequence of altered luminal $\mathrm{Ca}^{2+}$ content (Lloyd-Evans et al. 2008). It is also unclear which $\mathrm{Ca}^{2+}$ channel(s) in the lysosome membrane is most important in release of this luminal $\mathrm{Ca}^{2+}$ with evidence that mucolipins (especially transient receptor potential mucolipin 1, MCOLN1 (Dong et al. 2010)), two-pore channels (especially TPC2 (Grimm et al. 2014)), a voltage-gated calcium channel (Tian et al. 2015) and/or the purinergic receptor, P2X4 (Cao et al. 2015), may be involved. Intriguingly, cation transport through both mucolipin1 and TPC2 is activated by phosphatidylinositol 3,5-bisphosphate (PI(3,5)P2), which, in mammalian cells, is formed by the action of the enzyme PIKfyve on phosphatidylinositol 3-phosphate $(\mathrm{PI}(3) \mathrm{P}$ ) in endosomal membranes (Jin et al. 2016). It has been reported that a rapid increase in the concentration of $\mathrm{PI}(3,5) \mathrm{P} 2$ occurs on the membranes of late endocytic organelles immediately before they fuse (Li et al. 2013), although the specificity of the PI(3,5)P2 probe used in the studies leading to this conclusion has been questioned (Hammond et al. 2015). In addition, it has been argued that PI(3,5)P2 may be more important in regulating fission rather than fusion (see below).

Lysosomal $\mathrm{Ca}^{2+}$ release via mucolipin1 is also thought to be important for the fusion of autophagosomes with lysosomes, as are appropriate levels of $\mathrm{PI}(3,5) \mathrm{P} 2$ (Martens et al. 2016). Unlike $\mathrm{PI}(3,5) \mathrm{P} 2, \mathrm{PI}(4,5) \mathrm{P} 2$ is mostly found in the plasma membrane, but some can be generated at the lysosomal membrane where it can act as an inhibitor of $\mathrm{Ca}^{2+}$ transport through mucolipin1. Part of the cellular complement of the PI(4,5)P2 5-phosphatase 
OCRL (oculocerebrorenal syndrome of Lowe) is associated with mucolipin1 and maintains $\mathrm{PI}(4,5) \mathrm{P} 2$-free microdomains around this $\mathrm{Ca}^{2+}$ channel (De Leo et al. 2016). Thus, when OCRL activity is absent either as a result of experimental manipulation or in the disease Lowe syndrome, an unrestricted accumulation of $\mathrm{PI}(4,5) \mathrm{P} 2$ occurs on the lysosomal membrane with consequent inhibition of $\mathrm{Ca}^{2+}$ flux through mucolipin1 and inhibition of lysosome fusion with autophagosomes. This has been proposed as the reason why autophagosomes accumulate in cells from Lowe's syndrome patients. Local generation of $\mathrm{PI}(4,5) \mathrm{P} 2$ is also thought to play a role in lysosome re-formation from autolysosomes (see below), emphasizing the likely importance of spatiotemporal regulation of the concentration of phosphoinositides on the lysosomal membrane. A role for luminal acidity has also been proposed for fusion events undertaken by lysosomes and yeast vacuoles, but remains controversial as does the requirement for the $\mathrm{V}$ ATPase (vacuolar $\mathrm{H}^{+}$ATPase), which may involve an unconventional role of the $V_{0}$ sector interacting with SNARE proteins and contributing physically to membrane fusion (Coonrod et al. 2013; Mauvezin et al. 2015; Desfougeres et al. 2016).

Regulatory cytosolic factors are also implicated in lysosome fusion with endosomes and/or autophagosomes and include the VAMP7-binding protein, VARP (vacuolar protein sorting 9 ankyrin repeat protein) (Schafer et al. 2012), ATG14 (Diao et al. 2015)and EPG5 (ectopic P-granules autophagy protein 5) (Wang et al. 2016), which have effects on SNARE complex assembly and/or stabilization. The leucine-rich repeat kinases LRRK1 and LRRK2 have also been implicated in defective traffic to lysosomes via the endocytic and autophagy pathways. LRRK2 is highly expressed in brain, kidney and some immune cells. It localizes to several membrane-bound organelles on postGolgi membrane traffic pathways and regulates a subset of Rab GTPases (Steger et al. 2016). Autosomal dominant mutations in the gene encoding LRRK2 are the most common cause of familial forms of the neurodegenerative disorder, Parkinson's disease and are also associated with sporadic forms of the disease. LRRK1 is widely expressed, but less highly in brain than LRRK2. LRRK1 indirectly regulates Rab7 activity and is recruited to lysosomes by VAMP7 (Toyofuku et al. 2015). Lysosome fusion with both 
autophagosomes and endosomes is negatively regulated by RUBICON (Run domain BECLIN-1-interacting and cysteine-rich domain-containing protein), which binds to UVRAG (UV radiation-resistance associated gene product), when this component of VPS34 complex II (consisting of the phosphatidylinositol-3-kinase VPS34, VPS15, BECLIN-1 and UVRAG), is phosphorylated by mTORC1 (Kim et al. 2015). This results in inhibition of Rab7 and HOPS activity and has led to the suggestion that the mTORC1UVRAG pathway is an important regulatory axis through which cells coordinate autophagy and the endosome-lysosomal degradation pathway (Kim et al. 2015). In addition to possible nutritional regulation via mTORC1 (Antonioli et al. 2016), lysosome-autophagosome fusion is reduced when cells are incubated in high glucose as a result of increased addition of $\mathrm{O}$-linked-Nacetylglucosamine to SNAP29, which inhibits the formation of trans-SNARE complexes. Conversely, glucose starvation results in less modification of SNAP29 with O-linked-N-acetylglucosamine and increased formation of autolysosomes (Guo et al. 2014). Also implicated in regulating the efficiency of fusion with lysosomes are motor proteins, which are bound to organelles destined for fusion and move them along microtubules and/or actin filaments (van der Kant et al. 2013; Kruppa et al. 2016). Finally, it should be noted that inefficient degradation of macromolecules may itself reduce the efficiency of fusion via effects on membrane cholesterol (Fraldi et al. 2010) and also prevent lysosome re-formation (Bright et al. 1997; Bright et al. 2016; Schmid et al. 1999).

\subsection{Other lysosomal fusion events}

In addition to fusing with late endosomes and autophagosomes, lysosomes can also fuse with phagosomes, macropinosomes and the plasma membrane (reviewed in (Luzio et al. 2007)). Lysosome fusion with the plasma membrane is triggered by an increase in cytosolic $\mathrm{Ca}^{2+}$ concentration and is regulated by the $\mathrm{Ca}^{2+}$ sensor synaptotagmin VII, which restricts both the kinetics and extent of fusion and interacts with the core fusion machinery comprising the SNARE proteins syntaxin 4, SNAP23 and VAMP7 (Rao et al. 2004). The increased cytosolic $\mathrm{Ca}^{2+}$ concentration can occur as a result of plasma membrane damage causing $\mathrm{Ca}^{2+}$ influx. The resultant exocytosis of a peripheral population of lysosomes starts a plasma membrane sealing and re- 
modelling process that is essential for the survival of cells wounded by mechanical stress or attacked by some pathogens (Castro-Gomes et al. 2016). Lysosomal secretion is also regulated by the transcription factor TFEB, which can cause translocation of lysosomes to the plasma membrane and increased secretion, but the molecular mechanisms are unclear (Medina et al. 2011). Over-expression of TFEB in some cellular models of lysosomal storage disease results in increased lysosomal exocytosis and clearance of accumulated metabolites, suggesting TFEB as a therapeutic target in these diseases (Medina et al. 2011; Spampanato et al. 2013). Although all cell types seem to have the ability to fuse lysosomes with the plasma membrane, some cells have specialized "secretory lysosomes" or "lysosome-related organelles" (LROs). The variety of LROs and signaling pathways to trigger their secretion are reviewed in (Luzio et al. 2014).

\subsection{Lysosome re-formation and its regulation}

In contrast to the molecular machinery of fusion, less is known about the mechanism(s) by which lysososomes are re-formed from endolysosomes and autolysosomes. In both cases, tubulation and fission events have been suggested to occur. Some of these events are likely concerned with the recycling of membrane components e.g. SNAREs that should not be present on the re-formed lysosomes. However, others are necessary in the formation and scission, along their length, of proto-lysosomal tubules from which mature re-formed lysosomes are generated. In the re-formation of lysosomes from autolysosomes, the formation of protolysosomal tubules is regulated by mTORC1 (Yu et al. 2010; Rong et al. 2011) and their scission/vesiculation is mediated by the GTPase dynamin2 (Schulze et al. 2013). Currently, the best model for re-formation of lysosomes from autolysosomes comes from the results of experimental manipulations, which suggest that localized phosphoinositide generation on the autolysosome membrane causes the recruitment of the sorting adaptors AP-2 and AP-4, clathrin and the kinesin motor KIF5B to microdomains enriched in $\mathrm{PI}(4,5) \mathrm{P} 2$, which results in the formation and extension of protolysosomal tubules along microtubules (Rong et al. 2012; Du et al. 2016). One note of caution about this model is that much earlier experiments showed how easy it was to mis-target AP-2 and clathrin to intracellular compartments and away from the plasma membrane, 
where their recruitment and function is well understood, simply by adding GTP $\gamma S$ or excess $\mathrm{Ca}^{2+}$ (Seaman et al. 1993). Recently, it has been suggested that it is not alterations in mTORC1 activity per se that induces lysosome reformation, but the delivery to the autolysosome of mitochondrial DNA, which binds to TLR9 (toll-like receptor 9). This triggers an increase in local $\mathrm{PI}(4,5) \mathrm{P} 2$ concentration, resulting in the recruitment of AP-2 and clathrin (De Leo et al. 2016).

Additional clues about the machinery of lysosome re-formation have come from the study of cells from patients with lysosomal storage diseases. These are rare, inherited genetic defects, in many cases causing deficiencies in specific lysosomal acid hydrolases, but in others resulting in defects in lysosomal membrane proteins or nonenzymatic soluble lysosomal proteins. Cells from such patients contain membrane-bound, heterogeneous storage lesions, most probably abnormal endolysosomes/autolysosomes, filled with different contents in different diseases (Platt et al. 2012). Amongst lysosomal disease-associated proteins implicated in lysosome re-formation are Niemann-Pick type-C2 (Goldman and Krise 2010), LYST (lysosomal trafficking regulator) (Holland et al. 2014), the sorting adaptor AP-5 along with its associated proteins spatacsin and spastizin (Hirst et al. 2015), and also mucolipin1 (Miller et al. 2015), but molecular mechanisms remain elusive. In the case of mucolipin1, it has been proposed that this cation channel is responsible for the release of luminal $\mathrm{Ca}^{2+}$ and earlier in vitro experiments had shown that luminal $\mathrm{Ca}^{2+}$ is necessary for the formation of dense core lysosomes from endolysosomes (Pryor et al. 2000). As described above, $\mathrm{PI}(3,5) \mathrm{P} 2$ is an activator and $\mathrm{PI}(4,5) \mathrm{P} 2$ an inhibitor of this channel, which suggests at the very least tight spatiotemporal control of the concentrations of these phosphoinositides on the lysosomal membrane if fusion events and reformation events are to be properly coordinated. Certainly, depletion or pharmacological inhibition of PIKfyve, the enzyme synthesizing PI(3,5)P2 results in the formation of enlarged endocytic compartments with many characteristics of endolysosomes (reviewed in (Dove et al. 2009)) and small molecule activators of mucolipin1 can reverse the enlarged endolysosomal phenotype observed when a protein acting as a scaffold for PIKfyve is 
depleted (Zou et al. 2015). The $\mathrm{Ca}^{2+}$ released through mucolipin1 may be required for the extension and/or scission of the membrane bridges connecting endolysosomes to nascent lysosomes in the protolysosomal tubules (Miller et al. 2015). It has been argued that a good candidate for a $\mathrm{Ca}^{2+}$-regulated target is actin (Miller et al. 2015), the polymerisation state of which can also be affected by $\mathrm{PI}(4,5) \mathrm{P} 2$ (Saarikangas et al. 2010).

One of the most interesting aspects of lysosome re-formation is that it may be associated with an alteration in luminal acidity. For a long time it has been widely assumed that the lumen of all lysosomes is acidic $(\mathrm{pH} \leq 5)$, despite evidence from early ratiometric imaging experiments in the 1980s (Yamashiro and Maxfield 1987) and experiments on lysosomal enzyme function and acidophilic dye accumulation in the 1990s (Butor et al. 1995) suggesting that lysosomes exhibit a wide range of $\mathrm{pH}$. This has been reinforced by recent studies suggesting that a proportion of lysosomes (up to $\sim 25 \%$ ) have a luminal $\mathrm{pH}$ that is closer to neutral (>pH 6.5) (Johnson et al. 2016; Bright et al. 2016). These less acidic lysosomes are preferentially distributed closer to the cell periphery in cultured mammalian cells (Johnson et al. 2016) (Figure 2). The subcellular localization of lysosomes is determined by the balance between the small GTPases Rab7 and Arl8b which interact with kinesin and dynein microtubule motors via different effectors (Jordens et al. 2001; Rosa-Ferreira and Munro 2011; Fujiwara et al. 2016), as well as an ER-located ubiquitin ligase system that contributes to their immobilisation in the perinuclear region(Jongsma et al. 2016). Overexpression of the GTPases and/or their effectors can alter lysosome distribution within the cell, as can the use of motor inhibitors. It was found that if cells were experimentally manipulated to drive more lysosomes to the periphery, there was a reduction in their acidity(Johnson et al. 2016). Conversely, if lysosomes were driven towards the microtubule organizing centre/nucleus there was an increase in acidity. In a separate study, it was concluded that the more acidic lysosomes were in fact endolysosomes, acting as the principal sites of proteolytic degradation, with the less acidic lysosomes being in the latter stages of lysosome re-formation, such that the least acidic form a pool of terminal storage lysosomes (Bright et al. 2016). Although one of these studies concluded that lysosome position within the cell determines 
acidity and the other, that it is the stage of the lysosome fusion/regeneration cycle which is important, the conclusions are not incompatible. At present, little is known about the role, if any, of Rab7, Arl8b, their effectors and microtubule motor proteins in lysosome re-formation from endolysosomes. The reduced acidity of some lysosomes appears to be due to an increased passive (leak) permeability to protons together with reduced V-ATPase activity (Johnson et al. 2016). This could be due to recycling of the intact $V$ ATPase, as has been suggested for the generation of neural post-lysosome compartments in Dictyostelium discoideum (Carnell et al. 2011), or the separation of $V_{0}$ and $V_{1}$ sub-complexes of the V-ATPase, as is observed under nutritional control in yeast (Parra and Kane 1998). Interestingly, in yeast, the late endosomal/vacuolar phosphoinositide $\mathrm{PI}(3,5) \mathrm{P} 2$ has been shown to stabilize the $V_{0} / V_{1}$ interaction in yeast (Li et al. 2014). There may also be regulation of V-ATPase activity as a result of protein binding, one candidate being the Rab7 effector RILP (Rab-interacting lysosomal protein) (De Luca et al. 2014). In this context, it is interesting to note that whereas acidic juxtanuclear lysosomes/ endolysosomes are RAB7-positive, less acidic and more peripheral lysosomes are Rab7-negative (Johnson et al. 2016; Bright et al. 2016). Another protein observed to bind V-ATPase and potentially regulate activity is the interferon-induced protein IFITM3 (interferon-inducible transmembrane protein 3 ), which may be particularly important in regulating lysosomal acidity and function following viral infection (Wee et al. 2012).

\section{Lysosomal signaling and cell growth control}

The lysosome acts as an important site of nutrient sensing and metabolic regulation, because it is on the limiting membrane of the lysosome that the kinase activity of mTORC1 is regulated in a nutrient-, energy-, stressand growth factor-regulated manner to regulate the balance between anabolic and catabolic pathways within the cell (reviewed in (Zoncu et al. 2011b; Lim and Zoncu 2016; Perera and Zoncu 2016)). mTORC1 is a rapamycinsensitive multi-subunit protein complex that contains the PI3K-related serine/threonine protein kinase mTOR. mTOR also exists in an alternative rapamycin-insensitive protein complex called $\mathrm{mTORC} 2$ that phosphorylates the serine/threonine kinase AKT (also known as protein kinase B) in response 
to growth factor stimulation and participates in modulating many cellular functions including cell survival and actin dynamics (Laplante and Sabatini 2012). Whereas mTORC1 activation is associated primarily with the lysosome membrane, mTORC2 function has been localized to the plasma membrane (Ebner et al. 2017). The convergence of several growth factorinitiated signaling pathways on $\mathrm{mTORC} 1$ enables it to participate in many developmental and physiological processes and it is essential for early embryonic development. Some of these signaling pathways (e.g. insulin stimulation or low energy levels), result in the phosphorylation of a large protein complex, TSC (tuberous sclerosis complex), which regulates the nucleotide binding state of the small GTPase RHEB on the cytosolic surface of lysosomes and controls the kinase activation state of mTORC1 (Sengupta et al. 2010). However, independently of TSC, mTORC1 recruitment to the lysosome cytosolic surface is controlled by nutrient levels (most strongly by amino acids), through regulation of the nucleotide binding state and heterodimerization of the Rag family of small GTPases. Thus, it is the lysosome limiting membrane where diverse signal inputs are sensed and integrated to control both the localization of MTORC1 and subsequent activation of mTOR kinase activity to exert global effects on cell growth and metabolism. A consequence of the activation of mTORC1 is the phosphorylation of a vast array of substrates that control growth and metabolism. Well studied targets include the ribosomal protein S6 kinase and elF4E-binding protein 1, which are proteins that control distinct aspects of mRNA translation and thus control the rate of protein synthesis (Sonenberg and Hinnebusch 2009). Because of its ability to sense nutrient levels, mTORC1 controls the activation state of non-selective macroautophagy through phosphorylation of the autophagy-initiating kinase ULK1 (Kim et al. 2011). When nutrient supply is low, mTORC1 is turned off, thus relieving its inhibitory effect on autophagy and this liberates cellular sources of nutrients through bulk degradation of macromolecules. mTORC1 also controls the activity of several transcription factors including some that are implicated in lipid synthesis and mitochondrial metabolism as well as TFEB and TFE3, members of the MiTF/TFE transcription factor family. TFEB and TFE3 are phosphorylated by mTORC1 at the lysosomal surface and regulate lysosome 
biogenesis, lysosome secretion and autophagy (Raben and Puertollano 2016; Napolitano and Ballabio 2016).

\subsection{Lysosomal localization and activation of $m$ TORC1}

Two protein complexes, an obligate heterodimer of Rag GTPases and a multimeric complex called Ragulator, function together to localize mTORC1 to the lysosomal membrane. The Rag heterodimers comprise RagA or B with RagC or D. When RagA or B is bound to GTP, RagC or D is loaded with GDP. Ragulator is composed of 5 proteins, LAMTOR 1-5 (lysosomal adaptor and mTOR regulator 1-5) and acts both as a scaffold anchoring the Rag GTPases to the lysosomal membrane and as a guanine nucleotide exchange factor for RagA/B (Bar-Peled et al. 2012). Thus, in the presence of amino acids, Ragulator promotes the loading of GTP onto RagA/B, which dimerizes with GDP-loaded Rag C/D. It is likely that it is the GDP-loaded Rag C/D, which directly recruits $\mathrm{mTORC} 1$ to the lysosomal membrane (Tsun et al. 2013). It is proposed that recruitment of mTORC1 to the cytosolic surface of the lysosome brings it into close physical proximity to the small GTPase RHEB, which directly activates mTOR kinase activity. The nucleotide loading state of the Rag heterodimers is also regulated at the lysososomal membrane by a protein called GATOR1 (GTPase-activating protein towards Rags 1) (BarPeled et al. 2013), which promotes the inactive GDP-bound state of RagA/B. The activity of GATOR1 is under inhibitory control by a second complex called GATOR2, which itself is controlled by additional proteins including Sestrin2 homodimers and the CASTOR complex (dimer of GATSL1/2). Recently, it has been shown that GATOR1 complex recruitment to the lysosome surface is controlled by a complex termed KICSTOR (Peng et al. 2017; Wolfson et al. 2017). The nucleotide binding state of RagC/D has been shown to be regulated by the tumour suppressor protein folliculin, which forms a complex with FNIP1/2 (folliculin-interacting proteins1/2). Folliculin is proposed to function as a GTPase-activating protein for Rag C/D (Petit et al. 2013; Tsun et al. 2013), although the mechanism of GTPase activation remains to be elucidated.

A long-standing question is what are the precise mechanisms by which amino acids are sensed to control mTORC1 activation on the lysosome surface ? Changes in amino acid concentration in both the lumen of the 
lysosome and the cytosol can regulate the activity of mTORC1, although the signaling pathways are complex and far from completely understood (Manifava et al. 2016). The signaling pathway employed by luminal amino acids to stimulate Ragulator GEF activity towards RagA/B on the cytosolic side of the lysosome's limiting membrane requires both the V-ATPase and the sodium-coupled, amino acid-transporting, 11-pass trans-membrane protein SLC38A9. The V-ATPase binds Ragulator and the Rag GTPases in an amino acid-dependent manner and experimental inhibition of the V-ATPase prevents recruitment of $\mathrm{mTORC} 1$ to the lysosome in response to amino acids (Zoncu et al. 2011a). SLC38A9 may play a particularly important role in sensing arginine levels within the lysosome lumen (Jung et al. 2015; Rebsamen et al. 2015; Wang et al. 2015). It binds to the V-ATPase via its C-terminal transmembrane region and to Ragulator and the Rag GTPases via its N-terminal cytosolic domain and may act primarily as a transceptor rather than purely as a transporter. Other lysosomal amino acid transporters have also been implicated in mTORC1 activation (reviewed in (Lim and Zoncu 2016)).

A rise in cytosolic amino acid concentration results in Rag complex activation, in part through a reduction in RagA/B inhibition by the negative regulator GATOR1. A rise in the concentration of specific amino acids is detected by the cytosolic leucine sensor Sestrin2 and the cytosolic arginine sensor CASTOR, which become inhibited when bound to their respective amino acid ligands (Chantranupong et al. 2016; Wolfson et al. 2016). When not bound to amino acids, both Sestrin2 and CASTOR inhibit GATOR2 (the GATOR1 inhibitory complex described above), resulting in Rag complex inactivation. Thus, when Sestrin2 and CASTOR are bound by amino acids, the net effect is that GATOR2 is able to inhibit the GATOR1-dependent inhibition of RagA/B. The entirety of the lysosome membrane protein machinery responding to amino acids is shown in Figure 3 and includes both integral membrane proteins, the Ragulator/Rag/mTORC1 complexes and associated proteins on the cytosolic surface of the lysosome. It has been suggested that this entire machinery be referred to as the LYNUS (lysosome nutrient sensing) machinery (Settembre et al. 2013b). One interesting consequence of the critical role played by the lysosomal V-ATPase in amino acid signaling to mTORC1 is that it raises the question of whether 
juxtanuclear and peripheral lysosomes and/or organelles at different stages of the lysosome regeneration cycle play different roles in this signaling, given their difference in V-ATPase activity and luminal pH (Gowrishankar and Ferguson 2016). There is evidence that intracellular lysosome positioning coordinates metabolic responses to nutrient availability with plasma membrane signaling events (Korolchuk et al. 2011).

The regulation of $\mathrm{mTORC} 1$ activity by insulin and growth factors is mediated via phosphorylation of the TSC complex as mentioned above. The TSC complex is a heterotrimer of the tuberous sclerosis complex tumour suppressor genes TSC1 and TSC2 with TBC1D7 (Dibble et al. 2012). TSC functions as an inhibitor of mTORC1 by acting as a GAP (GTPase activating protein) towards the mTOR kinase activator RHEB. Insulin signaling results in release of TSC from the lysosomal surface following its phosphorylation by the protein kinase AKT (Menon et al. 2014), which is dependent on AKT recruitment to the membrane by interaction with phosphoinositides (Ebner et al. 2017). TSC activity can also be enhanced through phosphorylation via the LKB1/AMPK (liver kinase B1/AMP activated protein kinase) signalling axis in response to energy stress (Inoki et al. 2003), the activity of which has also been localized to the lysosome surface (Zhang et al. 2014).

Although the best studied signalling inputs to TSC are those downstream of growth factor receptor activation and energy stress, it has been shown that TSC recruitment to the lysosome surface is also controlled by amino acid availability, and may in fact be a general consequence of cellular stress (Demetriades et al. 2014; Demetriades et al. 2016). Thus, it is spatial control of TSC that contributes to the integration of growth factor signalling, nutrient regulation, and stress signalling and their role in mTORC1 activation on the lysosome surface.

\subsection{Lysosomal signalling to the nucleus: TFEB and the CLEAR network}

In addition to recruiting $\mathrm{MTORC} 1$ to the lysosome membrane, active Rag GTPases also promote recruitment of the transcription factor TFEB in an amino acid-dependent manner (Martina and Puertollano 2013). In fully fed cells, TFEB continuously cycles between lysosomes and the cytosol, such that when associated with the lysosome it can be phosphorylated by 
mTORC1 at several sites, including residue S211 (Settembre et al. 2012; Vega-Rubin-de-Celis et al. 2017). Phosphorylation at S211 promotes interaction with the cytosolic chaperone 14-3-3, resulting in a steady state in which the majority of TFEB is in the cytosol (Roczniak-Ferguson et al. 2012). Nutrient withdrawal or other treatments leading to lysosomal stress e.g. VATPase inhibition, lead to inactivation of $m T O R C 1$, since it is released from the lysosomal surface, thus reducing phosphorylation of TFEB. Nutrient withdrawal/lysosomal stress also cause the dephosphorylation of TFEB by the calcium-dependent phosphatase calcineurin, dissociation from 14-3-3 and transport into the nucleus (Figure 4). Activation of calcineurin results from the release of luminal $\mathrm{Ca}^{2+}$ from the lysosome via mucolipin1 (Medina et al. 2015). TFEB is a basic helix-loop-helix transcription factor which binds to a palindromic 10-bp (base pair) nucleotide motif, GTCACGTGAC, present (often in multiple copies) in the promoter region of many genes encoding lysosomal enzymes. The palindromic nucleotide motif has been named the CLEAR (coordinated lysosomal expression and regulation) element (Sardiello et al. 2009) and the extensive number of genes affected, the CLEAR network (Palmieri et al. 2011). This network provides a system that regulates the expression, import and activity of lysosomal enzymes, which control the degradation of proteins, glycosaminoglycans, sphingolipids and glycogen, is involved in the regulation of autophagy, exo- and endocytosis, phagocytosis and the immune response, as well as regulating some non-lysosomal enzymes/proteins involved in protein degradation and lipid metabolism (Palmieri et al. 2011; Settembre et al. 2013a). Other members of the members of the MiTF/TFE transcription factor family, in particular TFE3 which also binds CLEAR elements, are regulated in a very similar way to TFEB (reviewed in (Raben and Puertollano 2016; Napolitano and Ballabio 2016)). TFEB and TFE3 are partially redundant in their ability to induce lysosome biogenesis in response to starvation and both are necessary for a maximal response. However, overall MiTF/TFE transcription factors appear to have limited redundancy and some specific functions. Their ability to heterodimerize with each other has been a complication in studies of their function.

It should be noted that lysosome biogenesis is also affected by 
mTORC1 independent mechanisms. Thus, protein kinase $\mathrm{C}$ couples activation of TFEB with inactivation of the transcriptional repressor ZKSCAN3 via parallel signaling cascades (Li et al. 2016) and an mTORC1-independent pathway mediated via PERK (protein kinase RNA-like endoplasmic reticulum kinase), has been shown to regulate TFEB/TFE3 translocation to the nucleus in response to ER stress (Martina et al. 2016). Recently, it has been demonstrated that AKT modulates TFEB activity by phosphorylation at S467 and that trehalose, an mTOR-independent autophagy enhancer, promotes nuclear translocation of TFEB by inhibiting AKT (Palmieri et al. 2017). These observations are especially interesting because they have suggested that AKT control of TFEB activity may be a useful mTORC1-independent target for pharmacological treatment of neurodegenerative lysosomal storage diseases to stimulate cellular clearance of the storage material.

\section{Lysosomal $\mathrm{Ca}^{2+}$ signaling}

Mammalian, acidic lysosomes/endolysosomes contain a significant store of intracellular free $\mathrm{Ca}^{2+}$, measured as being $\sim 0.5 \mathrm{mM}$ (Christensen et al. 2002; Lloyd-Evans et al. 2008; Ronco et al. 2015). This is within the range of estimates of the steady state luminal free concentration in the ER, and is $>3$ orders of magnitude higher than the cytosolic $\mathrm{Ca}^{2+}$ concentration. Thus, release of $\mathrm{Ca}^{2+}$ through any of the identified lysosomal channels has the potential to affect a range of cytosolic functions. Regulated release of lysosomal $\mathrm{Ca}^{2+}$ is implicated in fusion/fission events and the activation of calcineurin to dephosphorylate TFEB and upregulate genes with CLEAR elements as described above. However, the effect of releasing lysosomal $\mathrm{Ca}^{2+}$ on cytosolic $\mathrm{Ca}^{2+}$ concentration can be amplified by stimulation of ER $\mathrm{Ca}^{2+}$ release, facilitating its involvement in a range of other cellular processes including muscle contraction, neurite extension and differentiation (reviewed in (Morgan et al. 2011; Penny et al. 2015)). $\mathrm{Ca}^{2+}$ release through two pore channels in the endolysosomal system has also been implicated in metastasis (Nguyen et al. 2017) and in Ebola virus entry into host cells (Sakurai et al. 2015). Defects in lysosomal $\mathrm{Ca}^{2+}$ signaling and homeostasis have been suggested to play a role in lysosomal storage disease pathogenesis (LloydEvans and Platt 2011). One of the most significant developments in understanding a role for lysosomes in intracellular signaling came from the 
discovery that release of $\mathrm{Ca}^{2+}$ from acidic LROs in sea urchin eggs is stimulated by the pyridine nucleotide metabolite NAADP (Clapper et al. 1987). Whilst the physiological production and degradation of NAADP is not fully understood, it clearly functions as an intracellular second messenger in mammalian cells (Yamasaki et al. 2005), not just in sea urchin eggs, and a major intracellular target activated by NAADP is the lysosomal two pore channel TPC2 (Pitt et al. 2010). The regulation of the release of $\mathrm{Ca}^{2+}$ through TPC2 is also be affected by lysosomal $\mathrm{Ca}^{2+}$ concentration and lysosomal $\mathrm{pH}$. As discussed above, the acidic lysosomal $\mathrm{pH}$ is generated through the activity of the lysosomal V-ATPase, with charge compensation provided via unspecified cation channels, the lysosomal $\mathrm{Cl}^{-} / \mathrm{H}^{+}$antiporter CIC-7/Ostm1 and/or alternative counter-ion pathways (Steinberg et al. 2010). In some cell types lysosomal $\mathrm{pH}$ can be regulated by signaling pathways affecting $\mathrm{V}$ ATPase trafficking or charge compensation e.g. pathways involving a cell surface $G$ protein-coupled receptor, cyclic AMP and protein kinase A (Lassen et al. 2016; Folts et al. 2016), thus potentially also affecting lysosomal $\mathrm{Ca}^{2+}$ release. Re-filling of lysosomal $\mathrm{Ca}^{2+}$ stores may also play a role in signaling. The lysosomal $\mathrm{Ca}^{2+} / \mathrm{H}^{+}$exchanger $\mathrm{CAX}$ has been shown to play a role in cell migration during frog development, but does not appear to have an ortholog in placental mammals (Melchionda et al. 2016). In mammalian cells the ER is the primary source of $\mathrm{Ca}^{2+}$ for the lysosome (Garrity et al. 2016) and it has been proposed that selective accumulation of $\mathrm{Ca}^{2+}$ released from the ER may allow lysosomes to play a role in shaping cytosolic $\mathrm{Ca}^{2+}$ signals caused by release of ER Ca ${ }^{2+}$ (Lopez-Sanjurjo et al. 2013). The functional relationship(s) between lysosomal and ER $\mathrm{Ca}^{2+}$ stores are likely affected by the close physical proximity of these organelles and the formation of ER-lysosome contact sites (Penny et al. 2015; Lopez-Sanjurjo et al. 2013; Ronco et al. 2015; Sbano et al. 2017). Membrane contact sites (MCSs) between intracellular organelles, especially those involving the ER, are currently the subject of much investigation (reviewed in (Gatta and Levine 2016; Zhang and Hu 2016; Hariri et al. 2016; Raffaello et al. 2016)), since they enable nonvesicular communication, for example for the transfer of cholesterol between endolysosomes and the ER (Du et al. 2011), as well as marking sites of organelle fission of both mitochondria (Friedman et al. 2011) and endosomes 
(Rowland et al. 2014) and regulating the final steps of autophagy (Wijdeven et al. 2016). In the context of lysosomal signaling, one especially interesting observation was the induction of NAADP-dependent microdomains of high $\mathrm{Ca}^{2+}$ concentration between lysosomes and the sarcoplasmic reticulum in response to beta-adrenoceptor activation in cardiac myocytes (Capel et al. 2015).

\section{Other lysososomal signaling pathways}

\subsection{Toll-like receptors}

Lysosomes play an important role in the innate immune system, through the function of an intracellular subgroup of the TLR (toll-like receptor) family of pattern recognition receptors, comprising TLR3,7,8 and 9 (reviewed in (Kawai and Akira 2010; Majer et al. 2016)). These type I integral membrane proteins are widely expressed, require proteolytic cleavage to become functional receptors and bind nucleic acids. This results in the activation of a signaling cascade from their cytosolic domains. TLRs play an important role in initiating and enhancing adaptive immune responses to invading pathogens. TLR9 is one of the best studied TLRs, including the regulation of its trafficking from the ER to lysosomes, and requires cleavage in an acidic environment by endolysosomal proteases to become functional. TLR9 binds unmethylated CpG motifs in DNA and in addition to its role in innate immunity, responding to bacterial or viral infection, it has also been implicated in regulation of the autophagic pathway, as described above, through recognition of mitochondrial DNA.

\subsection{Regulation of lysosome membrane permeability}

An aspect of lysosomal signaling that merits wider consideration is partial and selective permeabilisation of the limiting membrane which can trigger cell death as a consequence of cathepsin release into the cytosol (reviewed in (Serrano-Puebla and Boya 2016)). One relatively well studied instance is the post-lactational involution of the mammary gland caused by lysosome-mediated, non-apoptotic, programmed cell death. The key trigger of this process is milk itself, with a Stat3-dependent pathway involving increased phagocytic uptake of milk fat globules by mammary epithelial cells, resulting in degradation of milk triglycerides and the generation of an increased concentration of oleic acid that disrupts the lysosomal membrane 
enabling cathepsin release (Sargeant et al. 2014). Regulation of lysosomal membrane permeabilisation likely plays a wider role in health and disease although the complexities and molecular mechanisms are poorly understood (Serrano-Puebla and Boya 2016). In cancer, it has been suggested that minor lysosomal leakage may not necessarily be lethal and that release of lysosomal cathepsins may be anti-apoptotic (Pislar et al. 2015). In addition, what has been described as lysosome hyperactivity in some cancer cells can result in increased lysosomal membrane vulnerability - a frailty that might be exploited therapeutically by drugs that can induce lysosomal damage preferentially in cancer cells (reviewed in (Hamalisto and Jaattela 2016)).

\subsection{Lysosomal signaling, ageing and longevity}

Lysosomal dysfunction has long been associated with cellular ageing and reduced longevity in animals (reviewed in (Carmona-Gutierrez et al. 2016; Colacurcio and Nixon 2016)). Whilst much of this is associated with alterations in the degradative and signaling functions discussed above, it has been suggested that an additional signaling pathway between lysosomes and the nucleus may play a role. In Caenorhabditis elegans. increased life span occurs as a consequence of lysosomal production of the bioactive lipid oleoylethanolamide, which is translocated into the nucleus by a chaperone protein and affects the transcription of genes that regulate longevity. Interestingly, the components of this signaling pathway are conserved in mammals. (Folick et al. 2015).

\section{Conclusions}

Whilst the lysosome was for a long time simply regarded as the terminal degradative compartment of the cell's endocytic and autophagic pathways, it is clear that it is in fact a multifunctional signaling hub. The cell's lysosomal compartment is functionally heterogeneous and includes endolysosomes, autolysosomes, storage lysosomes and organelles at different stages of the lysosome fusion/regeneration cycle. It is in constant dynamic exchange with endosomal and autophagosomal compartments, links nutrient status to gene transcription, integrates hormonal and nutrient signaling, signals to other intracellular organelles, ensures plasma membrane integrity and plays a role in regulating cell death and in the ageing and longevity of both individual cells and the metazoan organism. There are many 
remaining important questions to address concerning the lysosomal compartment and signaling. A non-exhaustive list of such questions, where we currently have at best only partial answers, includes how the various fusion/fission events undertaken by organelles in the lysosomal compartment are regulated and coordinated, how lysosomal acidity is regulated, how calcium accumulation/release in the compartment is regulated, whether there is additional molecular machinery to be discovered in the signaling pathways between the lysosome, the nucleus and other organelles and whether there is physiologically significant heterogeneity in the signaling capacity of endolysosomes/lysosomes based on intracellular positioning and/or stage in the lysosome fusion/regeneration cycle.

\section{Acknowledgements}

GGH is supported by a Basic Research Fellowship from Parkinson Canada. Recent experimental work from JPL and NAB referred to in this Chapter is supported by UK MRC research grant MR/M010007/1. LJD is supported by a BBSRC industrial CASE studentship with GSK Research and Development Ltd. The Cambridge Institute for Medical Research is supported by Wellcome Trust Strategic Award 100140.

\section{Figure Legends}

Figure 1. The lysosome fusion/regeneration cycle. Electron-dense, terminal storage lysosomes fuse with late endosomes/MVBs to form catalytically active, acidic endolysosomes. Subsequent tubulation, maturation, and content condensation steps are involved in the regeneration/re-formation of storage lysosomes. A similar cycle occurs for the fusion of lysosomes with autophagosomes to form autolysosomes from which lysosomes are regenerated. Electron dense material is shaded in dark grey.

Figure 2. Ratiometric imaging of lysosomal pH in NRK cells. NRK (normal rat kidney) cells were incubated in tissue culture medium containing both $0.5 \mathrm{mg} / \mathrm{ml}$ Dextran-Oregon Green 488 as the acid-sensitive fluorochrome and $0.5 \mathrm{mg} / \mathrm{ml}$ Dextran-Alexa 647 as the acid-insensitive fluorochrome for $4 \mathrm{~h}$ 
followed by a $20 \mathrm{~h}$ chase in conjugate-free medium to load terminal endocytic compartments. Dual-fluorochrome ratiometric confocal microscopy showed that acidic organelles (blue) were more centrally located, whereas less acidic/more neutral organelles (cyan and green) were concentrated towards the cell periphery in a representative cell (a). To construct a $\mathrm{pH}$ calibration curve, cells were clamped at $\mathrm{pH}$ 4-7 in buffer containing $10 \mu \mathrm{M}$ nigericin and $10 \mu \mathrm{M}$ monensin for $5 \mathrm{~min}$ and representative confocal images are shown from a cell clamped at $\mathrm{pH} 7$ (b) or $\mathrm{pH} 4$ (c) using identical imaging parameters used to collect the unclamped image. Scale bar $=10 \mu \mathrm{m}$.

Figure 3. Regulation of mTORC1 activation on the lysosome surface. The mTORC1 complex is recruited to the lysosome surface through direct interaction with the $\operatorname{RagA} / \mathrm{B}(\mathrm{GTP})-\operatorname{Rag} \mathrm{C} / \mathrm{D}(\mathrm{GDP})$ (active state) heterodimer. The Rag heterodimer nucleotide loading state is under complex regulatory control, and responds to nutrient levels (especially amino acids). The Ragulator complex acts as a GEF towards RagA/B (thus promoting the active Rag dimer) and functions in concert with SLC38A9 and the V-ATPase in response to amino acid levels in the lysosome lumen. The GATOR1 complex acts as a GAP towards RagA/B (thus promoting the inactive Rag dimer) and is under regulatory control by the GATOR2 complex. GATOR2 inhibition of GATOR1 is regulated by Sestrin2 (SESN2) and CASTOR complexes binding to individual amino acids (Leu and Arg respecitively). The GATOR complexes are recruited to the lysosome surface by the KICSTOR complex. Folliculin (FLCN) and its interacting proteins FNIP1/2 are proposed to act as a GAP towards RagC/D (thus promoting the active Rag dimer). At the lysosome surface, the activation state of the mTOR kinase is regulated by the small GTPase RHEB. The TSC complex (TSC1/2, TBC1D7) acts as a GAP towards RHEB, and is regulated by signals downstream of growth factor receptors, energy levels, and cellular stress pathways. Collectively, the integrated regulation of $\mathrm{mTORC} 1$ activity on the lysosome surface by nutrients, energy levels, stress and growth signalling pathways exerts global control over the balance between catabolic (eg. autophagy, lysosome biogenesis) and anabolic cell growth pathways. 
Figure 4. Regulation of TFEB by lysosomal $\mathrm{Ca}^{2+}$. In fully fed cells, TFEB is phosphorylated by $\mathrm{mTORC} 1$ on the lysosomal membrane. Binding of phosphorylated TFEB by 14-3-3 in the cytosol prevents its entry into the nucleus (left). Upon starvation or lysosomal stress, mucolipin1 (MCOLN1) releases lysosomal $\mathrm{Ca}^{2+}$, which leads to local Calcineurin activation in the cytoplasm and TFEB dephosphorylation. Dephosphorylated TFEB cannot be bound by 14-3-3 proteins and translocates into the nucleus where it binds to CLEAR elements on the DNA and activates the transcription of lysosomal/autophagic genes (right).

\section{References}

Alonso V, Friedman PA (2013) Minireview: ubiquitination-regulated G proteincoupled receptor signaling and trafficking. Mol Endocrinol 27 (4):558572. doi:10.1210/me.2012-1404 me.2012-1404 [pii]

Antonioli M, Di Rienzo M, Piacentini M, Fimia GM (2016) Emerging Mechanisms in Initiating and Terminating Autophagy. Trends Biochem Sci. doi:10.1016/j.tibs.2016.09.008

Bar-Peled L, Chantranupong L, Cherniack AD, Chen WW, Ottina KA, Grabiner BC, Spear ED, Carter SL, Meyerson M, Sabatini DM (2013) A Tumor suppressor complex with GAP activity for the Rag GTPases that signal amino acid sufficiency to mTORC1. Science 340 (6136):11001106. doi:10.1126/science. 1232044

Bar-Peled L, Schweitzer LD, Zoncu R, Sabatini DM (2012) Ragulator is a GEF for the rag GTPases that signal amino acid levels to mTORC1. Cell 150 (6):1196-1208. doi:10.1016/j.cell.2012.07.032

Bento CF, Renna M, Ghislat G, Puri C, Ashkenazi A, Vicinanza M, Menzies FM, Rubinsztein DC (2016) Mammalian Autophagy: How Does It Work? Annu Rev Biochem 85:685-713. doi:10.1146/annurev-biochem060815-014556

Bowman SL, Shiwarski DJ, Puthenveedu MA (2016) Distinct G proteincoupled receptor recycling pathways allow spatial control of downstream G protein signaling. J Cell Biol 214 (7):797-806. doi:10.1083/jcb.201512068

Bright NA, Davis LJ, Luzio JP (2016) Endolysosomes Are the Principal Intracellular Sites of Acid Hydrolase Activity. Curr Biol 26 (17):22332245. doi:10.1016/j.cub.2016.06.046 S0960-9822(16)30687-X [pii]

Bright NA, Gratian MJ, Luzio JP (2005) Endocytic delivery to lysosomes mediated by concurrent fusion and kissing events in living cells. Curr Biol 15 (4):360-365. doi:S0960982205001053 [pii] 10.1016/j.cub.2005.01.049

Bright NA, Reaves BJ, Mullock BM, Luzio JP (1997) Dense core lysosomes can fuse with late endosomes and are re-formed from the resultant hybrid organelles. J Cell Sci 110 ( Pt 17):2027-2040 
Butor C, Griffiths G, Aronson NN, Jr., Varki A (1995) Co-localization of hydrolytic enzymes with widely disparate $\mathrm{pH}$ optima: implications for the regulation of lysosomal pH. J Cell Sci 108 ( Pt 6):2213-2219

Cao Q, Zhong XZ, Zou Y, Murrell-Lagnado R, Zhu MX, Dong XP (2015) Calcium release through $\mathrm{P} 2 \mathrm{X} 4$ activates calmodulin to promote endolysosomal membrane fusion. J Cell Biol 209 (6):879-894. doi:10.1083/jcb.201409071

Capel RA, Bolton EL, Lin WK, Aston D, Wang Y, Liu W, Wang X, Burton RA, Bloor-Young D, Shade KT, Ruas M, Parrington J, Churchill GC, Lei M, Galione A, Terrar DA (2015) Two-pore Channels (TPC2s) and Nicotinic Acid Adenine Dinucleotide Phosphate (NAADP) at LysosomalSarcoplasmic Reticular Junctions Contribute to Acute and Chronic beta-Adrenoceptor Signaling in the Heart. J Biol Chem 290 (50):3008730098. doi:10.1074/jbc.M115.684076

Carmona-Gutierrez D, Hughes AL, Madeo F, Ruckenstuhl C (2016) The crucial impact of lysosomes in aging and longevity. Ageing Res Rev 32:2-12. doi:10.1016/j.arr.2016.04.009

Carnell M, Zech T, Calaminus SD, Ura S, Hagedorn M, Johnston SA, May RC, Soldati T, Machesky LM, Insall RH (2011) Actin polymerization driven by WASH causes V-ATPase retrieval and vesicle neutralization before exocytosis. J Cell Biol 193 (5):831-839. doi:10.1083/jcb.201009119

Castro-Gomes T, Corrotte M, Tam C, Andrews NW (2016) Plasma Membrane Repair Is Regulated Extracellularly by Proteases Released from Lysosomes. PLoS One 11 (3):e0152583. doi:10.1371/journal.pone.0152583

Chantranupong L, Scaria SM, Saxton RA, Gygi MP, Shen K, Wyant GA, Wang T, Harper JW, Gygi SP, Sabatini DM (2016) The CASTOR Proteins Are Arginine Sensors for the mTORC1 Pathway. Cell 165 (1):153-164. doi:10.1016/j.cell.2016.02.035

Chou HT, Dukovski D, Chambers MG, Reinisch KM, Walz T (2016) CATCHR, HOPS and CORVET tethering complexes share a similar architecture. Nat Struct Mol Biol 23 (8):761-763. doi:10.1038/nsmb.3264 nsmb.3264 [pii]

Christensen KA, Myers JT, Swanson JA (2002) pH-dependent regulation of lysosomal calcium in macrophages. J Cell Sci 115 (Pt 3):599-607

Clapper DL, Walseth TF, Dargie PJ, Lee HC (1987) Pyridine nucleotide metabolites stimulate calcium release from sea urchin egg microsomes desensitized to inositol trisphosphate. J Biol Chem 262 (20):9561-9568

Colacurcio DJ, Nixon RA (2016) Disorders of lysosomal acidification-The emerging role of v-ATPase in aging and neurodegenerative disease. Ageing Res Rev 32:75-88. doi:10.1016/j.arr.2016.05.004

Coonrod EM, Graham LA, Carpp LN, Carr TM, Stirrat L, Bowers K, Bryant NJ, Stevens TH (2013) Homotypic vacuole fusion in yeast requires organelle acidification and not the V-ATPase membrane domain. Dev Cell 27 (4):462-468. doi:10.1016/j.devcel.2013.10.014

de Duve C (2005) The lysosome turns fifty. Nat Cell Biol 7 (9):847-849. doi:ncb0905-847 [pii] 10.1038/ncb0905-847

De Leo MG, Staiano L, Vicinanza M, Luciani A, Carissimo A, Mutarelli M, Di Campli A, Polishchuk E, Di Tullio G, Morra V, Levtchenko E, Oltrabella F, Starborg T, Santoro M, di Bernardo D, Devuyst O, Lowe M, Medina 
DL, Ballabio A, De Matteis MA (2016) Autophagosome-lysosome fusion triggers a lysosomal response mediated by TLR9 and controlled by OCRL. Nat Cell Biol 18 (8):839-850. doi:10.1038/ncb3386

De Luca M, Cogli L, Progida C, Nisi V, Pascolutti R, Sigismund S, Di Fiore PP, Bucci C (2014) RILP regulates vacuolar ATPase through interaction with the V1G1 subunit. J Cell Sci 127 (Pt 12):2697-2708.

doi: $10.1242 /$ jcs.142604

Demetriades C, Doumpas N, Teleman AA (2014) Regulation of TORC1 in response to amino acid starvation via lysosomal recruitment of TSC2. Cell 156 (4):786-799. doi:10.1016/j.cell.2014.01.024

Demetriades C, Plescher M, Teleman AA (2016) Lysosomal recruitment of TSC2 is a universal response to cellular stress. Nat Commun 7:10662. doi:10.1038/ncomms10662

Desfougeres Y, Vavassori S, Rompf M, Gerasimaite R, Mayer A (2016) Organelle acidification negatively regulates vacuole membrane fusion in vivo. Sci Rep 6:29045. doi:10.1038/srep29045

Diao J, Liu R, Rong Y, Zhao M, Zhang J, Lai Y, Zhou Q, Wilz LM, Li J, Vivona S, Pfuetzner RA, Brunger AT, Zhong Q (2015) ATG14 promotes membrane tethering and fusion of autophagosomes to endolysosomes. Nature 520 (7548):563-566. doi:10.1038/nature14147

Dibble CC, Elis W, Menon S, Qin W, Klekota J, Asara JM, Finan PM, Kwiatkowski DJ, Murphy LO, Manning BD (2012) TBC1D7 is a third subunit of the TSC1-TSC2 complex upstream of mTORC1. Mol Cell 47 (4):535-546. doi:10.1016/j.molcel.2012.06.009

Dong XP, Shen D, Wang X, Dawson T, Li X, Zhang Q, Cheng X, Zhang Y, Weisman LS, Delling M, Xu H (2010) PI(3,5)P(2) controls membrane trafficking by direct activation of mucolipin $\mathrm{Ca}(2+)$ release channels in the endolysosome. Nat Commun 1:38. doi:10.1038/ncomms1037

Dove SK, Dong K, Kobayashi T, Williams FK, Michell RH (2009) Phosphatidylinositol 3,5-bisphosphate and Fab1p/PIKfyve underPPIn endo-lysosome function. Biochem J 419 (1):1-13. doi:10.1042/BJ20081950

Du W, Su QP, Chen Y, Zhu Y, Jiang D, Rong Y, Zhang S, Zhang Y, Ren H, Zhang C, Wang X, Gao N, Wang Y, Sun L, Sun Y, Yu L (2016) Kinesin 1 Drives Autolysosome Tubulation. Dev Cell 37 (4):326-336. doi:10.1016/j.devcel.2016.04.014

Du X, Kumar J, Ferguson C, Schulz TA, Ong YS, Hong W, Prinz WA, Parton RG, Brown AJ, Yang H (2011) A role for oxysterol-binding proteinrelated protein 5 in endosomal cholesterol trafficking. J Cell Biol 192 (1):121-135. doi:10.1083/jcb.201004142

Ebner M, Lucic I, Leonard TA, Yudushkin I (2017) PI(3,4,5)P3 Engagement Restricts Akt Activity to Cellular Membranes. Mol Cell 65 (3):416-431 e416. doi:10.1016/j.molcel.2016.12.028

Edgar JR, Eden ER, Futter CE (2014) Hrs- and CD63-dependent competing mechanisms make different sized endosomal intraluminal vesicles. Traffic 15 (2):197-211. doi:10.1111/tra.12139

Eltschinger S, Loewith R (2016) TOR Complexes and the Maintenance of Cellular Homeostasis. Trends Cell Biol 26 (2):148-159. doi:10.1016/j.tcb.2015.10.003 
Fader CM, Sanchez DG, Mestre MB, Colombo MI (2009) TI-VAMP/VAMP7 and VAMP3/cellubrevin: two v-SNARE proteins involved in specific steps of the autophagy/multivesicular body pathways. Biochim Biophys Acta 1793 (12):1901-1916. doi:10.1016/j.bbamcr.2009.09.011 S01674889(09)00236-5 [pii]

Feng Y, He D, Yao Z, Klionsky DJ (2014) The machinery of macroautophagy. Cell Res 24 (1):24-41. doi:10.1038/cr.2013.168 cr2013168 [pii]

Folick A, Oakley HD, Yu Y, Armstrong EH, Kumari M, Sanor L, Moore DD, Ortlund EA, Zechner R, Wang MC (2015) Aging. Lysosomal signaling molecules regulate longevity in Caenorhabditis elegans. Science 347 (6217):83-86. doi:10.1126/science.1258857

Folts CJ, Scott-Hewitt N, Proschel C, Mayer-Proschel M, Noble M (2016) Lysosomal Re-acidification Prevents Lysosphingolipid-Induced Lysosomal Impairment and Cellular Toxicity. PLoS Biol 14

(12):e1002583. doi:10.1371/journal.pbio.1002583

Fraldi A, Annunziata F, Lombardi A, Kaiser HJ, Medina DL, Spampanato C, Fedele AO, Polishchuk R, Sorrentino NC, Simons K, Ballabio A (2010) Lysosomal fusion and SNARE function are impaired by cholesterol accumulation in lysosomal storage disorders. EMBO J 29 (21):36073620. doi:10.1038/emboj.2010.237

Friedman JR, Lackner LL, West M, DiBenedetto JR, Nunnari J, Voeltz GK (2011) ER tubules mark sites of mitochondrial division. Science 334 (6054):358-362. doi:10.1126/science.1207385

Fujiwara T, Ye S, Castro-Gomes T, Winchell CG, Andrews NW, Voth DE, Varughese KI, Mackintosh SG, Feng Y, Pavlos N, Nakamura T, Manolagas SC, Zhao H (2016) PLEKHM1/DEF8/RAB7 complex regulates lysosome positioning and bone homeostasis. JCI Insight 1 (17):e86330. doi:10.1172/jci.insight.86330

Garrity AG, Wang W, Collier CM, Levey SA, Gao Q, Xu H (2016) The endoplasmic reticulum, not the $\mathrm{pH}$ gradient, drives calcium refilling of lysosomes. Elife 5. doi:10.7554/eLife.15887

Gatta AT, Levine TP (2016) Piecing Together the Patchwork of Contact Sites. Trends Cell Biol. doi:10.1016/j.tcb.2016.08.010

Goh LK, Sorkin A (2013) Endocytosis of receptor tyrosine kinases. Cold Spring Harb Perspect Biol 5 (5):a017459.

doi:10.1101/cshperspect.a017459 a017459 [pii] 5/5/a017459 [pii]

Goldman SD, Krise JP (2010) Niemann-Pick C1 functions independently of Niemann-Pick C2 in the initial stage of retrograde transport of membrane-impermeable lysosomal cargo. J Biol Chem 285 (7):49834994. doi:10.1074/jbc.M109.037622

Gowrishankar S, Ferguson SM (2016) Lysosomes relax in the cellular suburbs. J Cell Biol 212 (6):617-619. doi:10.1083/jcb.201602082

Grimm C, Holdt LM, Chen CC, Hassan S, Muller C, Jors S, Cuny H, Kissing S, Schroder B, Butz E, Northoff B, Castonguay J, Luber CA, Moser M, Spahn S, Lullmann-Rauch R, Fendel C, Klugbauer N, Griesbeck O, Haas A, Mann M, Bracher F, Teupser D, Saftig P, Biel M, Wahl-Schott C (2014) High susceptibility to fatty liver disease in two-pore channel 2deficient mice. Nat Commun 5:4699. doi:10.1038/ncomms5699

Guo B, Liang Q, Li L, Hu Z, Wu F, Zhang P, Ma Y, Zhao B, Kovacs AL, Zhang Z, Feng D, Chen S, Zhang H (2014) O-GlcNAc-modification of SNAP- 
29 regulates autophagosome maturation. Nat Cell Biol 16 (12):12151226. doi:10.1038/ncb3066

Hamalisto S, Jaattela M (2016) Lysosomes in cancer-living on the edge (of the cell). Curr Opin Cell Biol 39:69-76. doi:10.1016/j.ceb.2016.02.009

Hammond GR, Takasuga S, Sasaki T, Balla T (2015) The ML1Nx2 Phosphatidylinositol 3,5-Bisphosphate Probe Shows Poor Selectivity in Cells. PLoS One 10 (10):e0139957. doi:10.1371/journal.pone.0139957

Hariri H, Ugrankar R, Liu Y, Henne WM (2016) Inter-organelle ERendolysosomal contact sites in metabolism and disease across evolution. Commun Integr Biol 9 (3):e1156278. doi:10.1080/19420889.2016.1156278

Hickey CM, Wickner W (2010) HOPS initiates vacuole docking by tethering membranes before trans-SNARE complex assembly. Mol Biol Cell 21 (13):2297-2305. doi:10.1091/mbc.E10-01-0044 E10-01-0044 [pii]

Hirst J, Edgar JR, Esteves T, Darios F, Madeo M, Chang J, Roda RH, Durr A, Anheim M, Gellera C, Li J, Zuchner S, Mariotti C, Stevanin G, Blackstone C, Kruer MC, Robinson MS (2015) Loss of AP-5 results in accumulation of aberrant endolysosomes: defining a new type of lysosomal storage disease. Hum Mol Genet 24 (17):4984-4996. doi: $10.1093 / \mathrm{hmg} / \mathrm{ddv} 220$

Holland P, Torgersen ML, Sandvig K, Simonsen A (2014) LYST affects lysosome size and quantity, but not trafficking or degradation through autophagy or endocytosis. Traffic 15 (12):1390-1405. doi:10.1111/tra.12227

Huotari J, Helenius A (2011) Endosome maturation. EMBO J 30 (17):34813500. doi:10.1038/emboj.2011.286 emboj2011286 [pii]

Inoki K, Zhu T, Guan KL (2003) TSC2 mediates cellular energy response to control cell growth and survival. Cell 115 (5):577-590

Itakura E, Kishi-Itakura C, Mizushima N (2012) The hairpin-type tail-anchored SNARE syntaxin 17 targets to autophagosomes for fusion with endosomes/lysosomes. Cell 151 (6):1256-1269. doi:10.1016/j.cell.2012.11.001 S0092-8674(12)01336-0 [pii]

Jiang P, Nishimura T, Sakamaki Y, Itakura E, Hatta T, Natsume T, Mizushima $\mathrm{N}$ (2014) The HOPS complex mediates autophagosome-lysosome fusion through interaction with syntaxin 17. Mol Biol Cell 25 (8):13271337. doi:10.1091/mbc.E13-08-0447

Jin N, Lang MJ, Weisman LS (2016) Phosphatidylinositol 3,5-bisphosphate: regulation of cellular events in space and time. Biochem Soc Trans 44 (1):177-184. doi:10.1042/BST20150174

Johnson DE, Ostrowski P, Jaumouille V, Grinstein S (2016) The position of lysosomes within the cell determines their luminal $\mathrm{pH}$. J Cell Biol 212 (6):677-692. doi:10.1083/jcb.201507112

Jongsma ML, Berlin I, Wijdeven RH, Janssen L, Janssen GM, Garstka MA, Janssen H, Mensink M, van Veelen PA, Spaapen RM, Neefjes J (2016) An ER-Associated Pathway Defines Endosomal Architecture for Controlled Cargo Transport. Cell 166 (1):152-166. doi:10.1016/j.cell.2016.05.078

Jordens I, Fernandez-Borja M, Marsman M, Dusseljee S, Janssen L, Calafat J, Janssen H, Wubbolts R, Neefjes J (2001) The Rab7 effector protein 
RILP controls lysosomal transport by inducing the recruitment of dynein-dynactin motors. Curr Biol 11 (21):1680-1685

Jung J, Genau HM, Behrends C (2015) Amino Acid-Dependent mTORC1 Regulation by the Lysosomal Membrane Protein SLC38A9. Mol Cell Biol 35 (14):2479-2494. doi:10.1128/MCB.00125-15

Kawai T, Akira S (2010) The role of pattern-recognition receptors in innate immunity: update on Toll-like receptors. Nat Immunol 11 (5):373-384. doi:10.1038/ni.1863

Khatter D, Raina VB, Dwivedi D, Sindhwani A, Bahl S, Sharma M (2015) The small GTPase Arl8b regulates assembly of the mammalian HOPS complex on lysosomes. J Cell Sci 128 (9):1746-1761. doi:10.1242/jcs.162651 jcs.162651 [pii]

Kim J, Kundu M, Viollet B, Guan KL (2011) AMPK and mTOR regulate autophagy through direct phosphorylation of Ulk1. Nat Cell Biol 13 (2):132-141. doi:10.1038/ncb2152

Kim YM, Jung CH, Seo M, Kim EK, Park JM, Bae SS, Kim DH (2015) mTORC1 phosphorylates UVRAG to negatively regulate autophagosome and endosome maturation. Mol Cell 57 (2):207-218. doi:10.1016/j.molcel.2014.11.013

Korolchuk VI, Saiki S, Lichtenberg M, Siddiqi FH, Roberts EA, Imarisio S, Jahreiss L, Sarkar S, Futter M, Menzies FM, O'Kane CJ, Deretic V, Rubinsztein DC (2011) Lysosomal positioning coordinates cellular nutrient responses. Nat Cell Biol 13 (4):453-460. doi:10.1038/ncb2204

Kruppa AJ, Kendrick-Jones J, Buss F (2016) Myosins, Actin and Autophagy. Traffic 17 (8):878-890. doi:10.1111/tra.12410

Laplante M, Sabatini DM (2012) mTOR signaling in growth control and disease. Cell 149 (2):274-293. doi:10.1016/j.cell.2012.03.017

Lassen KG, McKenzie CI, Mari M, Murano T, Begun J, Baxt LA, Goel G, Villablanca EJ, Kuo SY, Huang H, Macia L, Bhan AK, Batten M, Daly MJ, Reggiori F, Mackay CR, Xavier RJ (2016) Genetic Coding Variant in GPR65 Alters Lysosomal pH and Links Lysosomal Dysfunction with Colitis Risk. Immunity 44 (6):1392-1405.

doi:10.1016/j.immuni.2016.05.007

Li SC, Diakov TT, Xu T, Tarsio M, Zhu W, Couoh-Cardel S, Weisman LS, Kane PM (2014) The signaling lipid PI(3,5)P(2) stabilizes $\mathrm{V}(1)-\mathrm{V}(0)$ sector interactions and activates the V-ATPase. Mol Biol Cell 25 (8):1251-1262. doi:10.1091/mbc.E13-10-0563

Li X, Wang X, Zhang X, Zhao M, Tsang WL, Zhang Y, Yau RG, Weisman LS, Xu H (2013) Genetically encoded fluorescent probe to visualize intracellular phosphatidylinositol 3,5-bisphosphate localization and dynamics. Proc Natl Acad Sci U S A 110 (52):21165-21170. doi:10.1073/pnas.1311864110

Li Y, Xu M, Ding X, Yan C, Song Z, Chen L, Huang X, Wang X, Jian Y, Tang G, Tang C, Di Y, Mu S, Liu X, Liu K, Li T, Wang Y, Miao L, Guo W, Hao $X$, Yang $C$ (2016) Protein kinase $C$ controls lysosome biogenesis independently of mTORC1. Nat Cell Biol 18 (10):1065-1077. doi:10.1038/ncb3407

Lim CY, Zoncu R (2016) The lysosome as a command-and-control center for cellular metabolism. J Cell Biol 214 (6):653-664.

doi:10.1083/jcb.201607005 
Lin X, Yang T, Wang S, Wang Z, Yun Y, Sun L, Zhou Y, Xu X, Akazawa C, Hong W, Wang T (2014) RILP interacts with HOPS complex via VPS41 subunit to regulate endocytic trafficking. Sci Rep 4:7282. doi:10.1038/srep07282 srep07282 [pii]

Lloyd-Evans E, Morgan AJ, He X, Smith DA, Elliot-Smith E, Sillence DJ, Churchill GC, Schuchman EH, Galione A, Platt FM (2008) NiemannPick disease type $\mathrm{C} 1$ is a sphingosine storage disease that causes deregulation of lysosomal calcium. Nat Med 14 (11):1247-1255. doi:10.1038/nm.1876

Lloyd-Evans E, Platt FM (2011) Lysosomal Ca(2+) homeostasis: role in pathogenesis of lysosomal storage diseases. Cell Calcium 50 (2):200205. doi:10.1016/j.ceca.2011.03.010

Lopez-Sanjurjo CI, Tovey SC, Prole DL, Taylor CW (2013) Lysosomes shape Ins(1,4,5)P3-evoked Ca2+ signals by selectively sequestering Ca2+ released from the endoplasmic reticulum. J Cell Sci 126 (Pt 1):289-300. doi:10.1242/jcs.116103

Luzio JP, Hackmann Y, Dieckmann NM, Griffiths GM (2014) The biogenesis of lysosomes and lysosome-related organelles. Cold Spring Harb Perspect Biol 6 (9):a016840. doi:10.1101/cshperspect.a016840 a016840 [pii] 6/9/a016840 [pii]

Luzio JP, Pryor PR, Bright NA (2007) Lysosomes: fusion and function. Nat Rev Mol Cell Biol 8 (8):622-632. doi:nrm2217 [pii] 10.1038/nrm2217

MacDonald C, Stamnes MA, Katzmann DJ, Piper RC (2015) Tetraspan cargo adaptors usher $\mathrm{GPI}$-anchored proteins into multivesicular bodies. Cell Cycle 14 (23):3673-3678. doi:10.1080/15384101.2015.1100773

Majer O, Liu B, Barton GM (2016) Nucleic acid-sensing TLRs: trafficking and regulation. Curr Opin Immunol 44:26-33. doi:10.1016/j.coi.2016.10.003

Manifava M, Smith M, Rotondo S, Walker S, Niewczas I, Zoncu R, Clark J, Ktistakis NT (2016) Dynamics of mTORC1 activation in response to amino acids. Elife 5. doi:10.7554/eLife.19960

Martens S, Nakamura S, Yoshimori T (2016) Phospholipids in Autophagosome Formation and Fusion. J Mol Biol. doi:10.1016/j.jmb.2016.10.029

Martina JA, Diab HI, Brady OA, Puertollano R (2016) TFEB and TFE3 are novel components of the integrated stress response. EMBO J 35 (5):479-495. doi:10.15252/embj.201593428

Martina JA, Puertollano R (2013) Rag GTPases mediate amino aciddependent recruitment of TFEB and MITF to lysosomes. J Cell Biol 200 (4):475-491. doi:10.1083/jcb.201209135

Mauvezin C, Nagy P, Juhasz G, Neufeld TP (2015) Autophagosomelysosome fusion is independent of V-ATPase-mediated acidification. Nat Commun 6:7007. doi:10.1038/ncomms8007

McEwan DG, Dikic I (2015) PLEKHM1: Adapting to life at the lysosome. Autophagy 11 (4):720-722. doi:10.1080/15548627.2015.1034419

McEwan DG, Popovic D, Gubas A, Terawaki S, Suzuki H, Stadel D, Coxon FP, Miranda de Stegmann D, Bhogaraju S, Maddi K, Kirchof A, Gatti E, Helfrich MH, Wakatsuki S, Behrends C, Pierre P, Dikic I (2015) PLEKHM1 regulates autophagosome-lysosome fusion through HOPS complex and LC3/GABARAP proteins. Mol Cell 57 (1):39-54. doi:10.1016/j.molcel.2014.11.006 
Medina DL, Di Paola S, Peluso I, Armani A, De Stefani D, Venditti R, Montefusco S, Scotto-Rosato A, Prezioso C, Forrester A, Settembre C, Wang W, Gao Q, Xu H, Sandri M, Rizzuto R, De Matteis MA, Ballabio A (2015) Lysosomal calcium signalling regulates autophagy through calcineurin and TFEB. Nat Cell Biol 17 (3):288-299. doi:10.1038/ncb3114

Medina DL, Fraldi A, Bouche V, Annunziata F, Mansueto G, Spampanato C, Puri C, Pignata A, Martina JA, Sardiello M, Palmieri M, Polishchuk R, Puertollano R, Ballabio A (2011) Transcriptional activation of lysosomal exocytosis promotes cellular clearance. Dev Cell 21 (3):421-430. doi:10.1016/j.devcel.2011.07.016

Melchionda M, Pittman JK, Mayor R, Patel S (2016) Ca2+/H+ exchange by acidic organelles regulates cell migration in vivo. J Cell Biol 212 (7):803-813. doi:10.1083/jcb.201510019

Menon S, Dibble CC, Talbott G, Hoxhaj G, Valvezan AJ, Takahashi H, Cantley LC, Manning BD (2014) Spatial control of the TSC complex integrates insulin and nutrient regulation of mTORC1 at the lysosome. Cell 156 (4):771-785. doi:10.1016/j.cell.2013.11.049

Metcalf D, Isaacs AM (2010) The role of ESCRT proteins in fusion events involving lysosomes, endosomes and autophagosomes. Biochem Soc Trans 38 (6):1469-1473. doi:10.1042/BST0381469

Miller A, Schafer J, Upchurch C, Spooner E, Huynh J, Hernandez S, McLaughlin B, Oden L, Fares H (2015) Mucolipidosis type IV protein TRPML1-dependent lysosome formation. Traffic 16 (3):284-297. doi:10.1111/tra.12249

Morgan AJ, Platt FM, Lloyd-Evans E, Galione A (2011) Molecular mechanisms of endolysosomal Ca2+ signalling in health and disease. Biochem J 439 (3):349-374. doi:10.1042/BJ20110949

Napolitano G, Ballabio A (2016) TFEB at a glance. J Cell Sci 129 (13):24752481. doi:10.1242/jcs.146365

Nguyen ON, Grimm C, Schneider LS, Chao YK, Atzberger C, Bartel K, Watermann A, Ulrich M, Mayr D, Wahl-Schott C, Biel M, Vollmar AM (2017) Two-pore channel function is crucial for migration of invasive cancer cells. Cancer Res. doi:10.1158/0008-5472.CAN-16-0852

Nguyen TN, Padman BS, Usher J, Oorschot V, Ramm G, Lazarou M (2016) Atg8 family LC3/GABARAP proteins are crucial for autophagosomelysosome fusion but not autophagosome formation during PINK1/Parkin mitophagy and starvation. J Cell Biol 215 (6):857-874. doi:10.1083/jcb.201607039

Palmieri M, Impey S, Kang H, di Ronza A, Pelz C, Sardiello M, Ballabio A (2011) Characterization of the CLEAR network reveals an integrated control of cellular clearance pathways. Hum Mol Genet 20 (19):38523866. doi:10.1093/hmg/ddr306

Palmieri M, Pal R, Nelvagal HR, Lotfi P, Stinnett GR, Seymour ML, Chaudhury A, Bajaj L, Bondar VV, Bremner L, Saleem U, Tse DY, Sanagasetti D, Wu SM, Neilson JR, Pereira FA, Pautler RG, Rodney GG, Cooper JD, Sardiello M (2017) mTORC1-independent TFEB activation via Akt inhibition promotes cellular clearance in neurodegenerative storage diseases. Nat Commun 8:14338. doi:10.1038/ncomms14338 
Parra KJ, Kane PM (1998) Reversible association between the V1 and V0 domains of yeast vacuolar $\mathrm{H}+-A T P a s e$ is an unconventional glucoseinduced effect. Mol Cell Biol 18 (12):7064-7074

Peng M, Yin N, Li MO (2017) SZT2 dictates GATOR control of mTORC1 signalling. Nature. doi:10.1038/nature21378

Penny CJ, Kilpatrick BS, Eden ER, Patel S (2015) Coupling acidic organelles with the ER through $\mathrm{Ca}(2)(+)$ microdomains at membrane contact sites. Cell Calcium 58 (4):387-396. doi:10.1016/j.ceca.2015.03.006

Perera RM, Zoncu R (2016) The Lysosome as a Regulatory Hub. Annu Rev Cell Dev Biol 32:223-253. doi:10.1146/annurev-cellbio-111315-125125

Petit CS, Roczniak-Ferguson A, Ferguson SM (2013) Recruitment of folliculin to lysosomes supports the amino acid-dependent activation of Rag GTPases. J Cell Biol 202 (7):1107-1122. doi:10.1083/jcb.201307084

Pislar A, Perisic Nanut M, Kos J (2015) Lysosomal cysteine peptidases Molecules signaling tumor cell death and survival. Semin Cancer Biol 35:168-179. doi:10.1016/j.semcancer.2015.08.001

Pitt SJ, Funnell TM, Sitsapesan M, Venturi E, Rietdorf K, Ruas M, Ganesan A, Gosain R, Churchill GC, Zhu MX, Parrington J, Galione A, Sitsapesan $R$ (2010) TPC2 is a novel NAADP-sensitive Ca2+ release channel, operating as a dual sensor of luminal $\mathrm{pH}$ and $\mathrm{Ca} 2+$. J Biol Chem 285 (45):35039-35046. doi:10.1074/jbc.M110.156927

Platt FM, Boland B, van der Spoel AC (2012) The cell biology of disease: lysosomal storage disorders: the cellular impact of lysosomal dysfunction. J Cell Biol 199 (5):723-734. doi:10.1083/jcb.201208152

Platta HW, Stenmark H (2011) Endocytosis and signaling. Curr Opin Cell Biol 23 (4):393-403. doi:10.1016/j.ceb.2011.03.008

S0955-0674(11)00025-1 [pii]

Pols MS, ten Brink C, Gosavi P, Oorschot V, Klumperman J (2013) The HOPS proteins hVps41 and hVps39 are required for homotypic and heterotypic late endosome fusion. Traffic 14 (2):219-232. doi:10.1111/tra.12027

Pryor PR, Mullock BM, Bright NA, Gray SR, Luzio JP (2000) The role of intraorganellar $\mathrm{Ca}(2+)$ in late endosome-lysosome heterotypic fusion and in the reformation of lysosomes from hybrid organelles. J Cell Biol 149 (5):1053-1062

Pryor PR, Mullock BM, Bright NA, Lindsay MR, Gray SR, Richardson SC, Stewart A, James DE, Piper RC, Luzio JP (2004) Combinatorial SNARE complexes with VAMP7 or VAMP8 define different late endocytic fusion events. EMBO Rep 5 (6):590-595. doi:10.1038/sj.embor.7400150

7400150 [pii]

Raben N, Puertollano R (2016) TFEB and TFE3: Linking Lysosomes to Cellular Adaptation to Stress. Annu Rev Cell Dev Biol 32:255-278. doi:10.1146/annurev-cellbio-111315-125407

Raffaello A, Mammucari C, Gherardi G, Rizzuto R (2016) Calcium at the Center of Cell Signaling: Interplay between Endoplasmic Reticulum, Mitochondria, and Lysosomes. Trends Biochem Sci 41 (12):1035-1049. doi:10.1016/j.tibs.2016.09.001

Rao SK, Huynh C, Proux-Gillardeaux V, Galli T, Andrews NW (2004) Identification of SNAREs involved in synaptotagmin VII-regulated 
lysosomal exocytosis. J Biol Chem 279 (19):20471-20479.

doi:10.1074/jbc.M400798200

Rebsamen M, Pochini L, Stasyk T, de Araujo ME, Galluccio M, Kandasamy RK, Snijder B, Fauster A, Rudashevskaya EL, Bruckner M, Scorzoni S, Filipek PA, Huber KV, Bigenzahn JW, Heinz LX, Kraft C, Bennett KL, Indiveri C, Huber LA, Superti-Furga G (2015) SLC38A9 is a component of the lysosomal amino acid sensing machinery that controls mTORC1. Nature 519 (7544):477-481. doi:10.1038/nature14107

Roczniak-Ferguson A, Petit CS, Froehlich F, Qian S, Ky J, Angarola B, Walther TC, Ferguson SM (2012) The transcription factor TFEB links mTORC1 signaling to transcriptional control of lysosome homeostasis. Sci Signal 5 (228):ra42. doi:10.1126/scisignal.2002790

Ronco V, Potenza DM, Denti F, Vullo S, Gagliano G, Tognolina M, Guerra G, Pinton P, Genazzani AA, Mapelli L, Lim D, Moccia F (2015) A novel $\mathrm{Ca}(2)(+)$-mediated cross-talk between endoplasmic reticulum and acidic organelles: implications for NAADP-dependent $\mathrm{Ca}(2)(+)$ signalling. Cell Calcium 57 (2):89-100. doi:10.1016/j.ceca.2015.01.001

Rong Y, Liu M, Ma L, Du W, Zhang H, Tian Y, Cao Z, Li Y, Ren H, Zhang C, Li L, Chen S, Xi J, Yu L (2012) Clathrin and phosphatidylinositol-4,5bisphosphate regulate autophagic lysosome reformation. Nat Cell Biol 14 (9):924-934. doi:10.1038/ncb2557

Rong Y, McPhee CK, Deng S, Huang L, Chen L, Liu M, Tracy K, Baehrecke $\mathrm{EH}, \mathrm{Yu} \mathrm{L}$, Lenardo MJ (2011) Spinster is required for autophagic lysosome reformation and mTOR reactivation following starvation. Proc Natl Acad Sci U S A 108 (19):7826-7831. doi:10.1073/pnas.1013800108

Rosa-Ferreira C, Munro S (2011) Arl8 and SKIP act together to link lysosomes to kinesin-1. Dev Cell 21 (6):1171-1178. doi:10.1016/j.devcel.2011.10.007

Rowland AA, Chitwood PJ, Phillips MJ, Voeltz GK (2014) ER contact sites define the position and timing of endosome fission. Cell 159 (5):10271041. doi:10.1016/j.cell.2014.10.023

Saarikangas J, Zhao H, Lappalainen P (2010) Regulation of the actin cytoskeleton-plasma membrane interplay by phosphoinositides. Physiol Rev 90 (1):259-289. doi:10.1152/physrev.00036.2009

Sakurai Y, Kolokoltsov AA, Chen CC, Tidwell MW, Bauta WE, Klugbauer N, Grimm C, Wahl-Schott C, Biel M, Davey RA (2015) Ebola virus. Twopore channels control Ebola virus host cell entry and are drug targets for disease treatment. Science 347 (6225):995-998. doi:10.1126/science.1258758

Sancak Y, Peterson TR, Shaul YD, Lindquist RA, Thoreen CC, Bar-Peled L, Sabatini DM (2008) The Rag GTPases bind raptor and mediate amino acid signaling to mTORC1. Science 320 (5882):1496-1501. doi:10.1126/science.1157535 1157535 [pii]

Sardiello M, Palmieri M, di Ronza A, Medina DL, Valenza M, Gennarino VA, Di Malta C, Donaudy F, Embrione V, Polishchuk RS, Banfi S, Parenti G, Cattaneo E, Ballabio A (2009) A gene network regulating lysosomal biogenesis and function. Science 325 (5939):473-477. doi:10.1126/science.1174447 1174447 [pii] 
Sargeant TJ, Lloyd-Lewis B, Resemann HK, Ramos-Montoya A, Skepper J, Watson CJ (2014) Stat3 controls cell death during mammary gland involution by regulating uptake of milk fat globules and lysosomal membrane permeabilization. Nat Cell Biol 16 (11):1057-1068. doi:10.1038/ncb3043

Sbano L, Bonora M, Marchi S, Baldassari F, Medina DL, Ballabio A, Giorgi C, Pinton P (2017) TFEB-mediated increase in peripheral lysosomes regulates store-operated calcium entry. Sci Rep 7:40797. doi:10.1038/srep40797

Schafer IB, Hesketh GG, Bright NA, Gray SR, Pryor PR, Evans PR, Luzio JP, Owen DJ (2012) The binding of Varp to VAMP7 traps VAMP7 in a closed, fusogenically inactive conformation. Nat Struct Mol Biol 19 (12):1300-1309. doi:10.1038/nsmb.2414

Schmid JA, Mach L, Paschke E, GlossI J (1999) Accumulation of sialic acid in endocytic compartments interferes with the formation of mature lysosomes. Impaired proteolytic processing of cathepsin B in fibroblasts of patients with lysosomal sialic acid storage disease. J Biol Chem 274 (27):19063-19071

Schulze RJ, Weller SG, Schroeder B, Krueger EW, Chi S, Casey CA, McNiven MA (2013) Lipid droplet breakdown requires dynamin 2 for vesiculation of autolysosomal tubules in hepatocytes. J Cell Biol 203 (2):315-326. doi:10.1083/jcb.201306140

Seaman MN, Ball CL, Robinson MS (1993) Targeting and mistargeting of plasma membrane adaptors in vitro. J Cell Biol 123 (5):1093-1105

Sengupta S, Peterson TR, Sabatini DM (2010) Regulation of the mTOR complex 1 pathway by nutrients, growth factors, and stress. Mol Cell 40 (2):310-322. doi:10.1016/j.molcel.2010.09.026

Serrano-Puebla A, Boya P (2016) Lysosomal membrane permeabilization in cell death: new evidence and implications for health and disease. Ann N Y Acad Sci 1371 (1):30-44. doi:10.1111/nyas.12966

Settembre C, De Cegli R, Mansueto G, Saha PK, Vetrini F, Visvikis O, Huynh T, Carissimo A, Palmer D, Klisch TJ, Wollenberg AC, Di Bernardo D, Chan L, Irazoqui JE, Ballabio A (2013a) TFEB controls cellular lipid metabolism through a starvation-induced autoregulatory loop. Nat Cell Biol 15 (6):647-658. doi:10.1038/ncb2718

Settembre C, Fraldi A, Medina DL, Ballabio A (2013b) Signals from the lysosome: a control centre for cellular clearance and energy metabolism. Nat Rev Mol Cell Biol 14 (5):283-296. doi:10.1038/nrm3565

Settembre C, Zoncu R, Medina DL, Vetrini F, Erdin S, Huynh T, Ferron M, Karsenty G, Vellard MC, Facchinetti V, Sabatini DM, Ballabio A (2012) A lysosome-to-nucleus signalling mechanism senses and regulates the lysosome via mTOR and TFEB. EMBO J 31 (5):1095-1108. doi:10.1038/emboj.2012.32

emboj201232 [pii]

Sonenberg N, Hinnebusch AG (2009) Regulation of translation initiation in eukaryotes: mechanisms and biological targets. Cell 136 (4):731-745. doi:10.1016/j.cell.2009.01.042

Sorkin A, Goh LK (2008) Endocytosis and intracellular trafficking of ErbBs. Exp Cell Res 314 (17):3093-3106. doi:10.1016/j.yexcr.2008.08.013 
Spampanato C, Feeney E, Li L, Cardone M, Lim JA, Annunziata F, Zare H, Polishchuk R, Puertollano R, Parenti G, Ballabio A, Raben N (2013) Transcription factor EB (TFEB) is a new therapeutic target for Pompe disease. EMBO Mol Med 5 (5):691-706.

doi:10.1002/emmm.201202176

Steger M, Tonelli F, Ito G, Davies P, Trost M, Vetter M, Wachter S, Lorentzen E, Duddy G, Wilson S, Baptista MA, Fiske BK, Fell MJ, Morrow JA, Reith AD, Alessi DR, Mann M (2016) Phosphoproteomics reveals that Parkinson's disease kinase LRRK2 regulates a subset of Rab GTPases. Elife 5. doi:10.7554/eLife.12813

Steinberg BE, Huynh KK, Brodovitch A, Jabs S, Stauber T, Jentsch TJ, Grinstein S (2010) A cation counterflux supports lysosomal acidification. J Cell Biol 189 (7):1171-1186. doi:10.1083/jcb.200911083

Tian X, Gala U, Zhang Y, Shang W, Nagarkar Jaiswal S, di Ronza A, Jaiswal M, Yamamoto S, Sandoval H, Duraine L, Sardiello M, Sillitoe RV, Venkatachalam K, Fan H, Bellen HJ, Tong C (2015) A voltage-gated calcium channel regulates lysosomal fusion with endosomes and autophagosomes and is required for neuronal homeostasis. PLoS Biol 13 (3):e1002103. doi:10.1371/journal.pbio.1002103

Toyofuku T, Morimoto K, Sasawatari S, Kumanogoh A (2015) Leucine-Rich Repeat Kinase 1 Regulates Autophagy through Turning On TBC1D2Dependent Rab7 Inactivation. Mol Cell Biol 35 (17):3044-3058. doi:10.1128/MCB.00085-15

Tsun ZY, Bar-Peled L, Chantranupong L, Zoncu R, Wang T, Kim C, Spooner E, Sabatini DM (2013) The folliculin tumor suppressor is a GAP for the RagC/D GTPases that signal amino acid levels to mTORC1. Mol Cell 52 (4):495-505. doi:10.1016/j.molcel.2013.09.016

van der Kant $R$, Fish A, Janssen L, Janssen H, Krom S, Ho N, Brummelkamp T, Carette J, Rocha N, Neefjes J (2013) Late endosomal transport and tethering are coupled processes controlled by RILP and the cholesterol sensor ORP1L. J Cell Sci 126 (Pt 15):3462-3474. doi:10.1242/jcs. 129270

van der Kant R, Jonker CT, Wijdeven RH, Bakker J, Janssen L, Klumperman J, Neefjes J (2015) Characterization of the Mammalian CORVET and HOPS Complexes and Their Modular Restructuring for Endosome Specificity. J Biol Chem 290 (51):30280-30290. doi:10.1074/jbc.M115.688440 M115.688440 [pii]

Vega-Rubin-de-Celis S, Pena-Llopis S, Konda M, Brugarolas J (2017) Multistep regulation of TFEB by MTORC1. Autophagy:0. doi:10.1080/15548627.2016.1271514

Wang S, Tsun ZY, Wolfson RL, Shen K, Wyant GA, Plovanich ME, Yuan ED, Jones TD, Chantranupong L, Comb W, Wang T, Bar-Peled L, Zoncu R, Straub C, Kim C, Park J, Sabatini BL, Sabatini DM (2015) Metabolism. Lysosomal amino acid transporter SLC38A9 signals arginine sufficiency to mTORC1. Science 347 (6218):188-194. doi:10.1126/science.1257132

Wang Z, Miao G, Xue X, Guo X, Yuan C, Wang Z, Zhang G, Chen Y, Feng D, $\mathrm{Hu}$ J, Zhang H (2016) The Vici Syndrome Protein EPG5 Is a Rab7 Effector that Determines the Fusion Specificity of Autophagosomes 
with Late Endosomes/Lysosomes. Mol Cell 63 (5):781-795.

doi:10.1016/j.molcel.2016.08.021

Wartosch L, Gunesdogan U, Graham SC, Luzio JP (2015) Recruitment of VPS33A to HOPS by VPS16 Is Required for Lysosome Fusion with Endosomes and Autophagosomes. Traffic 16 (7):727-742. doi:10.1111/tra.12283

Wee YS, Roundy KM, Weis JJ, Weis JH (2012) Interferon-inducible transmembrane proteins of the innate immune response act as membrane organizers by influencing clathrin and v-ATPase localization and function. Innate Immun 18 (6):834-845.

doi:10.1177/1753425912443392

White IJ, Bailey LM, Aghakhani MR, Moss SE, Futter CE (2006) EGF stimulates annexin 1-dependent inward vesiculation in a multivesicular endosome subpopulation. EMBO J 25 (1):1-12. doi:10.1038/sj.emboj.7600759

Wijdeven RH, Janssen H, Nahidiazar L, Janssen L, Jalink K, Berlin I, Neefjes $\mathrm{J}$ (2016) Cholesterol and ORP1L-mediated ER contact sites control autophagosome transport and fusion with the endocytic pathway. Nat Commun 7:11808. doi:10.1038/ncomms11808

Wolfson RL, Chantranupong L, Saxton RA, Shen K, Scaria SM, Cantor JR, Sabatini DM (2016) Sestrin2 is a leucine sensor for the mTORC1 pathway. Science 351 (6268):43-48. doi:10.1126/science.aab2674

Wolfson RL, Chantranupong L, Wyant GA, Gu X, Orozco JM, Shen K, Condon KJ, Petri S, Kedir J, Scaria SM, Abu-Remaileh M, Frankel WN, Sabatini DM (2017) KICSTOR recruits GATOR1 to the lysosome and is necessary for nutrients to regulate $\mathrm{mTORC} 1$. Nature. doi:10.1038/nature21423

Woodman PG, Futter CE (2008) Multivesicular bodies: co-ordinated progression to maturity. Curr Opin Cell Biol 20 (4):408-414. doi:10.1016/j.ceb.2008.04.001 S0955-0674(08)00072-0 [pii]

Yamasaki M, Thomas JM, Churchill GC, Garnham C, Lewis AM, Cancela JM, Patel S, Galione A (2005) Role of NAADP and cADPR in the induction and maintenance of agonist-evoked $\mathrm{Ca} 2+$ spiking in mouse pancreatic acinar cells. Curr Biol 15 (9):874-878. doi:10.1016/j.cub.2005.04.033

Yamashiro DJ, Maxfield FR (1987) Acidification of morphologically distinct endosomes in mutant and wild-type Chinese hamster ovary cells. J Cell Biol 105 (6 Pt 1):2723-2733

Yu L, McPhee CK, Zheng L, Mardones GA, Rong Y, Peng J, Mi N, Zhao Y, Liu Z, Wan F, Hailey DW, Oorschot V, Klumperman J, Baehrecke EH, Lenardo MJ (2010) Termination of autophagy and reformation of lysosomes regulated by mTOR. Nature 465 (7300):942-946. doi:10.1038/nature09076

Zhang CS, Jiang B, Li M, Zhu M, Peng Y, Zhang YL, Wu YQ, Li TY, Liang Y, Lu Z, Lian G, Liu Q, Guo H, Yin Z, Ye Z, Han J, Wu JW, Yin H, Lin SY, Lin SC (2014) The lysosomal v-ATPase-Ragulator complex is a common activator for AMPK and mTORC1, acting as a switch between catabolism and anabolism. Cell Metab 20 (3):526-540.

doi:10.1016/j.cmet.2014.06.014 
Zhang $\mathrm{H}$, Hu J (2016) Shaping the Endoplasmic Reticulum into a Social Network. Trends Cell Biol 26 (12):934-943.

doi:10.1016/j.tcb.2016.06.002

Zoncu R, Bar-Peled L, Efeyan A, Wang S, Sancak Y, Sabatini DM (2011a) mTORC1 senses lysosomal amino acids through an inside-out mechanism that requires the vacuolar $\mathrm{H}(+)$-ATPase. Science 334 (6056):678-683. doi:10.1126/science.1207056

Zoncu R, Efeyan A, Sabatini DM (2011b) mTOR: from growth signal integration to cancer, diabetes and ageing. Nat Rev Mol Cell Biol 12 (1):21-35. doi:10.1038/nrm3025

Zou J, Hu B, Arpag S, Yan Q, Hamilton A, Zeng YS, Vanoye CG, Li J (2015) Reactivation of Lysosomal Ca2+ Efflux Rescues Abnormal Lysosomal Storage in FIG4-Deficient Cells. J Neurosci 35 (17):6801-6812.

doi:10.1523/JNEUROSCI.4442-14.2015 
Endolysosome

Late endosome/ MVB

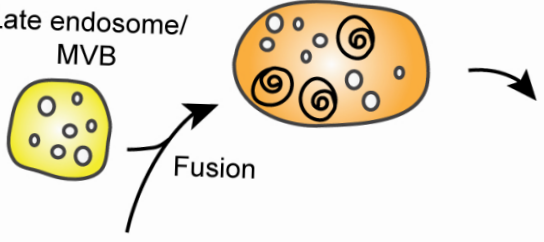

Terminal/ storage ysosome
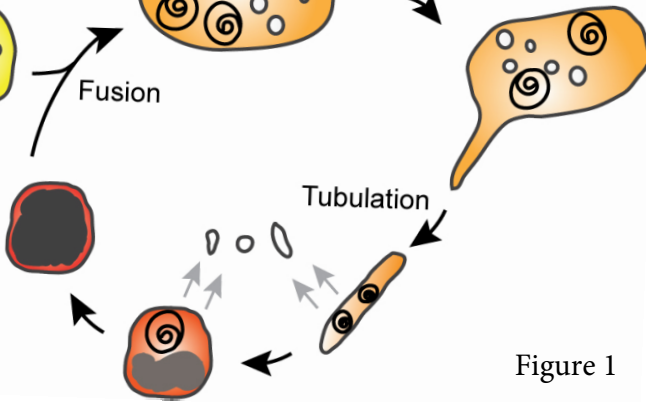

Figure 1 


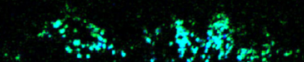

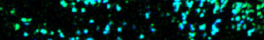

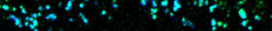

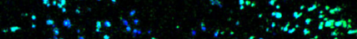

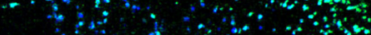

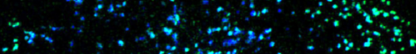

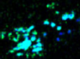

Figure 2

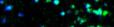

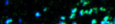

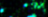

$x^{2}+2$

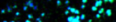

$x$ in $\rightarrow$

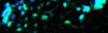

$\because \mathrm{AH}$

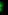

$+2+2,+30=$

$\therefore: \therefore, \quad 0=$

$=-54$

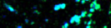

et.

$x_{x \rightarrow 3}$ 
Starvation, lysosomal stress, etc.

\section{TFEB}

Nucleus

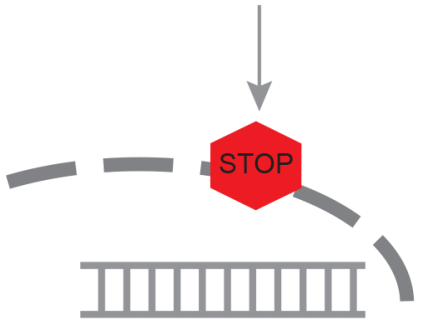

\section{TFEB}

Figure 4

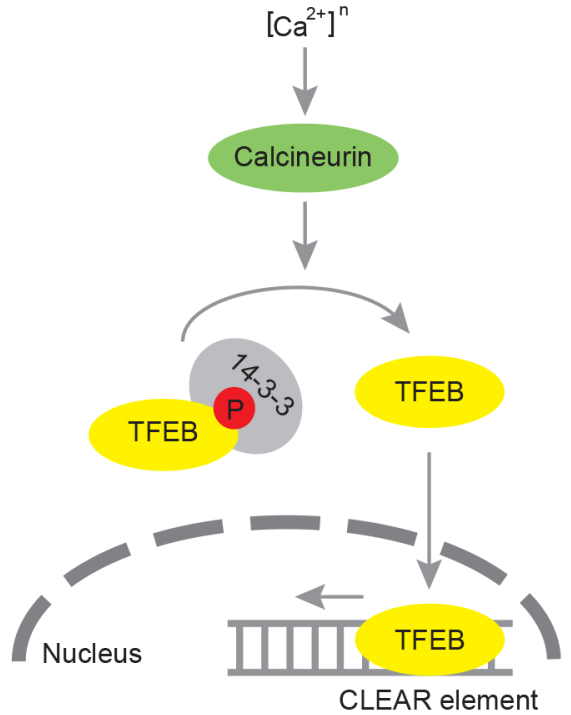

Lysosomal/autophagic gene expression 